\title{
Deformation and energy absorption of additively manufactured functionally graded thickness thin-walled circular tubes under lateral crushing
}

\author{
Ahmad Baroutaji $^{1(*)}$, Arun Arjunan ${ }^{1}$, Mark Stanford ${ }^{1}$, John Robinson ${ }^{1}$, Abdul Ghani Olabi ${ }^{2,3}$ \\ ${ }^{1}$ School of Engineering, University of Wolverhampton, Telford Innovation Campus, TF2 9NT, UK \\ ${ }^{2}$ Dept. of Sustainable and Renewable Energy Engineering, University of Sharjah, P.O. Box 27272, Sharjah, \\ UAE \\ ${ }^{3}$ School of Engineering and Applied Science, Aston University, Birmingham B4 7ET, UK
}

\begin{abstract}
Functionally graded thickness (FGT) is an innovative concept to create light-weight structures with better material distribution and promising energy absorption characteristics suitable for vehicle crashworthiness applications. Accordingly, this paper suggests innovative circular tubes with inplane thickness gradient along their perimeter and assesses their crashworthiness behaviour under lateral loading. Three different designs of circular tubes with thickness gradient were considered in which the locations of maximum and minimum thicknesses are varied. Selective laser melting method of additive manufacturing was used to manufacture the different tubes. Two different bulk powders including titanium (Ti6Al4V) and aluminium (AlSi10Mg) were used in the manufacturing process. Quasi-static crush experiments were conducted on the laser melted tubes to investigate their crushing and energy absorption behaviour. The energy absorption characteristics of the different FGT tubes were calculated and compared against a uniform thickness design. The results revealed that the best crashworthiness metrics were offered by FGT titanium tube in which the maximum thickness regions were along the horizontal and vertical directions while the minimum thickness regions were at an angle of $45^{\circ}$ with respect to the loading direction. The aforementioned tube was found to absorb $79 \%$ greater energy per unit mass than its uniform thickness counterpart. Finally, with the aid of numerical simulations and surrogate modelling techniques, multi-objective optimisation and parametric analysis were conducted on the best FGT tube. The influences of the geometrical parameters on the crashworthiness responses of the best FGT structure were explored and the optimal thickness gradient parameters were determined. The results reported in this paper provide valuable guidance on the design of FGT energy absorption tubes for lateral deformation.
\end{abstract}

Keywords: Functionally graded thickness, Thin-walled structures, Energy absorption, Quasi-static loading, crashworthiness, Additive manufacturing, Selective laser melting.

\section{* Corresponding author}

Dr Ahmad Baroutaji

School of Engineering, University of Wolverhampton, Telford Innovation Campus, Priorslee, Telford, TF2 9NT, UK

Tel: +44 (0)1902 322981; fax: +44 (0)1902 323843

E-mail address: ahmad.baroutaji2@ mail.dcu.ie 


\section{Introduction}

Over the past years, significant research efforts were directed towards understanding the deformation behaviour of traditional and innovative thin-walled tubes to employ them in the crashworthiness applications related to different sectors including automotive, aerospace, and defence [1-3]. Thin-walled tubes are widely used as deformable protective elements due to their lightweight, outstanding energy absorption, and low fabrication costs [1]. These structures dissipate the kinetic energy resulted from impact loading through irreversible plastic strain deformation hence maintaining the structural integrity of a vehicle and enhancing the passenger safety.

The majority of studies on the crashworthiness of thin-walled tubes focused on simple tubes with either circular or square cross-section under axial, lateral and bending loading [4-8]. The axial deformation of thin-walled structures was the most investigated one due to its significant energy absorbing potential where the majority of the structure's material undergoes plastic deformation. It was reported that the axial deformation can offer up to approximately 10 times more specific energy absorption than that of the lateral or bending deformation of the same specimen [2]. The main reason for the low energy absorption of lateral deformation is that it only yields a small number of plastic hinges during the crushing process leading to limited plastic strain zones confined around those plastic hinges [9-11]. However, lateral deformation mode is inevitable in many protective structures such as those used at front or side of vehicles and therefore more research work is needed to enhance the crashworthiness performance under such loading conditions.

The advances in the automotive industry necessitate developing lightweight and highly efficient energy absorption components to provide the required safety for modern vehicles. Thus, innovative versions of thin-walled structures with more sophisticated shapes and material started to be used as energy absorption structures such as functionally graded thickness [12-15], foam-filled [16,17], nested [10,18,19], corrugated [20], and multi-cell structures [19,21-23]. Functionally graded thickness (FGT) tubes are attractive structures with a non-uniform material distribution allowing for enhanced crashworthiness performance without increasing weight. Consequently, the FGT tubes are vital for developing lightweight but safe vehicles with reduced fuel consumption and less environmental effects. The crashworthiness performance of FGT tubes under axial or bending loading was presented in many studies [24-33]. Zhang et al. [24] assessed the energy absorbing performance of functionally graded thickness square tubes under axial loading. The cross-section of the tested samples featured a thicker corner where the plastic deformation takes place. The authors found that the tubes with a thickness gradient can absorb 30-35\% more energy per unit mass than the uniform thickness tube without increasing the initial peak force. Zhang et al. [34] also examined the axial crushing behaviour of tapered circular tubes with thickness gradient along their length. 
The FGT frusta tubes were compared with uniform thickness tubes where it was found that the FGT specimen performed more favourably, with 30-40\% higher specific energy absorption (SEA) and 26\% greater energy absorbing efficiency (CFE). Baykasoglu and Cetin [29] examined the influence of thickness-gradient patterns on the crashworthiness performance of axially loaded circular tubes. The study showed that FGT tubes have superior energy absorption characteristics compared to their uniform thickness counterparts. It was also reported that crashworthiness metrics of the FGT tubes can be improved with the appropriate selection of thickness-gradient parameters. Pang et al. [32] studied the axial crushing behaviour of FGT multi-cell square tubes and found that the thickness gradient may effectively decrease the initial peak crushing force without sacrificing the energy absorption capability of the structure. Li et al. [35] compared the crashworthiness of FGT and standard circular tubes with and without foam fillings when subjected to oblique loading with multiple loading angles. It was observed that the FGT tubes had lower initial peak force values than their uniform thickness counterparts for all loading angles providing advantageous to vehicle design applications due to the high possibility of oblique loads in road accidents. Sun et al. [36] analysed the performance of FGT tubes under dynamic lateral bending loading. The studied tube featured a circular cross-section with thickness gradient increasing towards the centre of the tube placing the thicker region at the impactor (punch) location. It was observed that the FGT tube had improved crashworthiness metrics compared to a tube of uniform thickness as both specific SEA and CFE were increased. Generally, all the aforementioned investigations have reported significant improvements in the energy absorption performance of structures with a thickness gradient compared to standard ones with uniform thickness. However, despite the superior performance, no attempt was made to apply the FGT concept to the cross-section of laterally loaded circular tubes. Those structures are expected to address the relatively poor performance of laterally loaded tubes yielding higher energy absorption capacity.

Generally, the manufacturing of structures with a thickness gradient is more complicated than the traditional uniform thickness ones. Normally, advanced manufacturing processes such as tailorwelded blank (TWB), tailor rolling blank (TRB), tailor hot stamping (THS) and additive manufacturing (AM) are used to produce the thin-walled structures with graded properties $[15,30,37,38]$. Selective laser melting (SLM) of AM with its significant design freedom has found its way to crashworthiness field through developing metallic structural components that cannot easily be obtained via the traditional fabrication techniques. SLM helps in fulfilling various demands for modern products such as light-weighting, greater functionality, and shorter design-tomanufacture time [39]. AlSi10Mg and Ti6Al4V are the most commonly used alloys for additive manufacturing via SLM and they have received increased applications in the automotive and aerospace industries [39]. The mechanical properties of the SLM parts are influenced by many 
factors including powder properties, melting and solidification rate of the material, building orientation, SLM process parameters, and heat treatment [40]. Controlling and optimising the aforementioned parameters may yield SLM parts with exceptional mechanical properties. For example, the mechanical properties of heat-treated SLM AlSi10Mg were reported to be superior to those casted alloys [41]. Also, SLM AlSi10Mg alloys exhibited better dynamic properties than those of the cast alloy, reaching almost two times the dynamic yield strength and four times the dynamic tensile strength [42]. The main downside of the laser melted parts is the lack of ductility due to the residual stresses generated during the SLM process. However, the post-SLM heat treatment process can improve the material's ductility but the heat treatment type and parameters should be selected carefully to ensure the balance between the strength and the ductility of the material.

SLM can be used to manufacture thin-walled tubes as well as lattice structures for both loadbearing and plastic deformation applications [43-45]. Alkhatib et al [46] used direct metal laser sintering to manufacture sinusoidally corrugated energy absorbers from AlSi10Mg material powder. Mohamed et al [47] also employed the same technique to create circular tubes with slits at the impact end acting as crush initiators. Osman el al [48], Jin el al [49], Zhang el al [50] adopted AM for manufacturing lattice metamaterial suitable for energy absorption applications. Obviously, AM provides distinct advantages over the traditional fabrication methods for creating complex shaped FGT structures.

In this paper, the crush performance of circular tubes with in-plane thickness gradient under lateral loading is to be examined experimentally and numerically. Such structures were never considered in the literature before despite their potential to address the poor energy absorption performance associated with the lateral deformation of the standard structures with uniform thickness. Parametric and optimisation studies are also conducted to fully comprehend the influence of thickness grading factors on the crashworthiness responses and determining those that lead to best performance.

\section{Experimental analysis}

\subsection{Specimens}

In this study, uniform thickness (UT) and functionally graded thickness (FGT) thin-walled short length tubes, or rings, were considered for lateral deformation. The UT tube features a uniform thickness whereas the FGT tubes have varying thicknesses along their perimeter as shown in Figure 1. Three different FGT designs, namely FGT1, FGT2, and FGT3, were conceived by altering the locations of the maximum and minimum thicknesses within the cross-section. All the FGT designs were symmetrical around the horizontal and vertical directions. In FGT1 design, the maximum 
thickness is located along the horizontal and vertical directions while the minimum thickness is located at an angle of $45^{\circ}$ with respect to the horizontal axis. In FGT2 and FGT3 designs, the locations of maximum thickness and minimum thicknesses are exchanged between the horizontal and vertical directions. For the various FGT designs, the tube's thickness was changed linearly between the locations of the maximum and minimum thicknesses. All the tested tubes have the same outer diameter of $100 \mathrm{~mm}$, and masses of $100 \mathrm{~g}$ and $60 \mathrm{~g}$ for Ti6Al4V and AlSi10Mg samples, respectively. The tubes dimensions are selected to be within the range used for the lateral deformation of circular tubes [4].

\subsection{SLM manufacturing process and Material}

The UT and FGT tubes were manufactured from titanium (Ti6Al4V) and aluminium (AlSi10Mg) based bulk powders using the SLM process. The chemical compositions of both materials are listed in Table 1. EOS M290 SLM machine occupied with a $400 \mathrm{~W}$ laser beam was used for laser melting of both powders. The process parameters such as laser exposure, scan speed, layer thickness and hatch distance were set as per the recommendations of the manufacturer to obtain a fully dense product (approx. 99.8\%). The main process parameters for both materials are summarised in Table 2. In standard SLM practise, it is recommended that the building platform should match the powder feedstock and therefore titanium and aluminium building platforms were used for Ti6Al4V and AlSi10Mg samples, respectively. Normally in SLM, Z-axis is the building direction while the scanning takes place in the XY plane which is perpendicular to the building direction (z-axis) as shown in Figure 2. The build orientation shown in Figure 2 was used for all samples in this study to reduce SLM support structures and resultant additional build time and post-processing requirements. The X-rotated laser scanning strategy was employed during the SLM process. The powder in the first layer was melted at an inclined angle of $67^{\circ}$ with respect to $\mathrm{x}$-direction (horizontal direction). For the successive layers, the orientation of the laser beam was rotated by 67

${ }^{o}$ in each layer till building the full specimen. The same scanning strategy was used for all tubes manufactured in this study. Post SLM, the samples were separated from the building base by electric discharge machining (EDM). No surface defects or geometrical imperfection were observed for the SLM-manufactured tubes. Finally, with an aim of relieving the residual stresses generated during the laser melting process, the manufactured tubes were heat treated where the heat treatment temperature and duration were set as per the recommendations stated in the material data sheet of the manufacturer. The heat treatment was completed in an argon inert atmosphere for the Ti samples and air atmosphere for the Al samples. A summary of heat treatment procedures is shown in Table 3. 
In addition to the tubes, dog bone tensile samples were also manufactured using the same bulk powders, i.e. Ti6Al4V and AlSi10Mg, under identical SLM process parameters. Standard tensile tests using a universal test machine were undertaken to obtain the mechanical properties of the material. The true stress-strain curves of both materials along with tensile samples are shown in Figure 3 whereas the mechanical properties are tabulated in Table 4.

\subsection{Crush test set-up}

The Zwick-1474 universal materials testing machine was used to conduct the quasi-static experimental crush tests on the respective UT and FGT tubes. The machine is capable of providing a maximum loading capacity of $100 \mathrm{kN}$. The tested tube was placed between the upper and lower platens of the machine and the crushing process was achieved through the upward motion of lower platen. The loading force is measured by a load cell mounted on the upper crosshead of the machine. To ensure that the conducted tests do not involve any dynamic effects, the moving speed of the lower platen was set at $10 \mathrm{~mm} / \mathrm{min}$, which is within the range of $0.5-15 \mathrm{~mm} / \mathrm{min}$ used in comparable studies for quasi-static compression tests $[4,5,10]$. The force and displacement were measured every $0.1 \mathrm{~ms}$ during each crushing test.

\subsection{Crashworthiness metrics}

The crashworthiness performance of the UT and FGT tubes under the lateral loading was assessed through calculating three main metrics namely; specific energy absorption (SEA), crush force efficiency (CFE), and crush displacement efficiency (CDE). These metrics are the most commonly used in the field for evaluating the crashworthiness [51].

The SEA is the energy absorbed per unit mass $(m)$ and it can be written as shown in Eq. 1:

$$
S E A=\frac{E A}{m}
$$

Where EA is the energy absorption during the lateral crushing and it is given by Eq. 2 :

$$
E A=\int_{0}^{\delta} F(x) d x
$$

Where $F(x)$ and $\delta$ are the instantaneous load and deformation distance of the tube respectively.

CFE is the ratio between the mean crush force (MCF) and the peak crush force (PCF) and it is calculated using Eq. 3

$$
C F E=\frac{M C F}{P C F}
$$

Generally, a good crashworthiness design should yield high SEA and CFE. 
$\mathrm{CDE}$ is the last indicator that was considered to compare the energy absorption performance of the energy absorption systems. CDE can be calculated as the total crush displacement $\left(\delta_{\text {total }}\right)$ measured up to the point of fracture divided by the unreformed length of the tube which was selected to be the outer diameter of the tube (D) and thus CDE can be expressed as stated in Eq. 4

$$
C D E=\frac{\delta_{\text {total }}}{D}
$$

The CDE indicator describes the amount of material that can be used during the crushing process and the bigger value indicates a better performance.

\subsection{Experimental results and discussion}

\subsubsection{Crush behaviour and deformation mode}

Figure 4 exhibits the force-displacement responses of UT and FGT tubes obtained from the crushing tests. The tubes were loaded laterally until a fracture happened in the tube which was sensed through the sudden drop in the value of force and hence the test was stopped. Apart from FTG2 design, the other designs have all shown typical responses under the lateral loading despite having different geometrical shapes and materials. The crush responses consist of two distinct phases namely; elastic and plastic, respectively. In the elastic phase, the force increases linearly and sharply to its characteristic 'initial collapse load'. For UT and FGT1 configurations, following the elastic phase, the tubes started to deform plastically and the crushing force increased gradually to reach its maximum magnitude at the end of the plastic phase and before tube's fracture. The force increase in the plastic region can be attributed to two main reasons including material strain hardening and geometrical changes in the tube during the deformation process. FGT3 design showed an almost flat crush response in the plastic region for the two materials where the force stays more or less constant with increasing the displacement. For the FGT2 tube, a fracture happened directly after reaching the initial collapse load with almost no sign of any plastic region.

The initial collapse load, or the force required to initiate the plastic deformation, in the laterally loaded circular tubes can be calculated as in Eq.5 [52]

$$
P_{o}=\frac{2 \sigma_{y} t^{2} L}{D}
$$

Where $\mathrm{D}$ is the tube diameter, $\sigma_{y}$ is yield stress of the material, $\mathrm{t}$ is the tube thickness at the location of the plastic hinge; $\mathrm{L}$ is the width of the tube. By inspecting the force-displacement curves, it can be seen that the initial collapse load of FGT1 design is higher than the others. This can be attributed to the fact that the FGT1 tube has the highest thickness at the location of the plastic hinge among all the designs. Additionally, the rate of increase of the crushing force with respect to displacement in the plastic region is higher in those designs with higher thicknesses at the location of the plastic 
hinge. This trend is basically due to the fact that the material strain hardening effect becomes greater in the thicker tubes as they have more material in the plastic zone.

Despite the two different materials used to manufacture the tested samples, the different designs in the two materials groups showed a comparable trend in terms of force-displacement response during the lateral deformation. This behaviour could be due to the fact that the tubes were manufactured using SLM process parameters that yield almost fully dense tubes with relatively similar grain structure.

The typical deformation mechanism of the laterally loaded circular tubes involves four plastic hinges. Two of these hinges are generated at the location of the maximum bending moment which is located along the horizontal line while the other two are generated at the contact points between the tube and the platens. Hence, the crushing mode of the laterally loaded circular tube is a plastic bending around the plastic hinges. Figure 5 shows the initial and final deformation modes of all samples tested in this study. As it can be seen from the figure, the tested samples were fractured at different locations. The fracture normally occurs at the weak zones that are subjected to high loading (forces or moments) but has less material to resist these forces. For the FGT1 design, the crack was initiated in the minimum thickness zone located at an angle of $45^{\circ}$ with respect to the horizontal line. Similarly, the catastrophic failure of FGT3 design took place at the location of small thickness identified along the horizontal line. The UT design was fractured at the location of horizontal plastic hinges because of the extreme plastic deformation developed in that zone. The fracture of the FGT2 happened at the bottom end which also had the minimum thickness.

\subsubsection{Crashworthiness evaluation}

Figure 6 shows the calculated crashworthiness metrics namely; SEA, CFE, and CDE for all the designs investigated in this paper. These metrics were calculated based on the force-displacement responses presented in Figure 4. By inspecting the SEA response, it is clear that the FGT1 absorbs the highest amount of energy per unit mass among all other designs in both material groups. For the Ti group, the FGT1 tube exhibits 79\%, 523\%, and 235\% greater SEA than the UT, FGT2, and FGT3 tubes, respectively. This trend can be attributed to the fact that the FGT1 has a higher thickness at the zones that undergo higher plastic strains and hence it has more material to deform plastically and participate in the energy dissipation process.

By comparing the CFE of the different designs, it can clearly be seen that the designs in $\mathrm{Al}$ group, represented by the blue bar in Figure 6 (b), outperform those in Ti group. Al-FGT3 tube exhibits the highest CFE magnitude among all other tubes. This trend is due to the favourable crush response offered by Al-FGT3 tube where the crush force remains almost constant in the postcollapse stage as it can be seen from Figure 4. The FGT1 design also shows very good CFE 
response which is only 5\% and 8\% less than that of Al-FGT3 tube for Al and Ti tubes, respectively. It should be noted that CFE metric is directly linked to the shape of force-displacement response and the tubes with more flat post-collapse responses, such as Al-FGT3, offer higher CFE values than the other tubes.

In terms of CDE behaviour, Al-UT and Ti-FGT1 tubes were the best performing structures with CDE of around $42 \%$. The tubes with FGT2 design exhibited the lowest CDE with only $9 \%$ and $16 \%$ for $\mathrm{Al}$ and Ti materials, respectively. The poor CDE performance observed for FGT2 design is due to crack initiations during the early stages of plastic deforming as indicated before. Overall, the CDE response for all SLM manufactured structures discussed in this paper is relatively low. This is due to the fact that the SLM process induces residual stresses that causes cracks to appear along the various stages of the deformation process. This issue could be addressed by optimising the SLM process parameters and the subsequent heat treatment to improve the ductility of the produced tubes and delaying the cracks initiation till the final stages of the deformation stroke allowing the tubes to absorb a greater amount of energy. Optimising the SLM and the heat treatment processes are beyond the scope of this paper and are suggested for future work efforts. Also, it should be noted that the additive manufacturing might not be the ideal manufacturing technique for energy absorption structures, particularly if the design is simple, i.e. uniform thickness design, and can be produced using the traditional manufacturing methods. The classically manufactured tube, such as the ones investigated in [9], may offer higher crush displacement efficiency compared to additively manufactured one without experiencing any cracks or failure due to its high ductility. The higher crushing distance allows the tube to absorb a greater amount of energy during the plastic deformation. However, the importance of the SLM method comes from its capability to produce designs with more complex geometry, i.e. functionally graded tubes, with higher energy absorption capability than the simple design.

From the results discussed above, the titanium tube with FGT1 design seems to offer excellent crashworthiness performance including highest SEA, highest CDE, and third highest CFE among all tested tubes and thus it was deemed to be the best performing energy absorbing tube. Ti-FGT1 tube, with its superior performance compared to other designs, can reduce the overall weight and material cost without losing crashworthiness and this makes it as weight/cost-effective candidate for vehicle crashworthiness applications.

\section{Simulation and optimisation}

With the aim of generating the design guidelines and finding the optimal configuration of the best performing tube investigated in this study, i.e. Ti-FGT1, finite element method (FEM) and design of experiment (DoE) techniques are employed in this section. Finite element models were 
first created and validated and then they were used in conjunction with DoE to develop metamodels of the crashworthiness responses. Subsequently, the developed meta-models were used in the multi-objective optimisation formulation to seek the optimal geometrical factors of the tube that yield the best crashworthiness performance. Parametric analysis was also conducted with the help of the developed meta-models to understand the role of each geometrical parameter in the crashworthiness behaviour.

\subsection{FE model description}

The Finite Element (FE) models of Ti-UT and Ti-FGT1 tubes were created using implicit finite element code, ANSYS. ANSYS has been used previously in literature to analyse the energy absorption performance of thin-walled structures due to its capability in capturing the crushing behaviour of tubes [4,5]. The FE model, as shown in Figure 7, is comprised of three main components including, two rigid bodies representing the upper and lower crushing platens, and one deformable thin-walled tube representing the energy absorber. 3D solid element with large strains and deformation capabilities was used to mesh the tube. A mesh convergence study was performed to determine the optimal mesh density and it was found that an element size of $2 \mathrm{~mm}$ was able to produce a converged solution within a reasonable time. The lower base was constrained to move vertically along the $y$-axis while the movement of the upper base was set to zero in all translational and rotational directions. A non-linear surface to surface contact algorithm with a friction coefficient of 0.2 was employed for all contact pairs to represent the interactions between the tube and the bases $[4,10]$. The loads were defined by applying a predefined displacement on the moving base. Large deformation option was activated to allow the tubes to undergo very high strains. Symmetry boundary conditions were utilised for all created models to reduce computational solution cost.

The bilinear isotropic hardening material model was adopted to represent the mechanical behaviour of the Ti6AL4V material. The mechanical properties of the material model were assigned based on the standard tensile tests results shown in Figure 3 and Table 4. A value of 2221.2 MPa was used for the Tangent modulus to model the post-yield response of the material. No specific fracture models or failure criterion was considered in the material model and the crashworthiness metrics were extracted from the crush simulations at CDE of $40 \%$ and $32 \%$ for FGT1 and UT designs, respectively. These values were selected based on the experimental observations discussed earlier which showed that the structural failure of FGT1 and UT designs occurs at CDE greater than the chosen ones. Modelling the fracture behaviour of heat-treated SLM Ti6Al4V alloys in ANSYS requires implementing complex material constitutive relations and obtaining damage parameters that are beyond the scope of this paper and could be considered in the future research work. 


\subsection{FE model validation}

To validate the FE model, the model predictions in terms of crush response and crashworthiness metrics were compared against the experimental measurements reported in section 2.5 . Figure 8 compares experimental and numerical force-displacement curves for the UT and FGT1 designs of Ti alloy. As can be seen, Figure 8 reveals an excellent agreement between the experimental and numerical results.

The deformation modes of the specimens obtained from the numerical simulation and experimental tests are also compared in Figure 8. It can be observed that the deformation modes of UT and FGT1 tubes are well captured by the FE models where the simulated patterns are almost identical to the experimental ones.

Table 5 shows the values of SEA and PCF extracted from the experimental tests data and the FE simulations. It can be seen that the percentage errors are insignificant for both responses where the highest errors for SEA and PCF were only $4.2 \%$ and $2.2 \%$, respectively.

Overall, the comparison between the numerical and experimental results indicates that the crashworthiness predictions of the FE models are accurate and the developed FE models are reliable and can be used as a tool to analyse the crush behaviour of the tubes under the lateral loading. Subsequently, the FE model was adopted to conduct the crush simulations required for constructing the meta-models of the crashworthiness responses.

\subsection{Geometry parameterisation of FGT1 design}

The first step of finding the optimal crashworthiness configuration of FGT1 design is to describe its geometry using key parameters. As it was described in section 2.1, the maximum thickness of FGT1 is located along the horizontal axis whilst the minimum thickness is located at an angle of $45^{\circ}$ with respect to the horizontal. The geometry of the FGT1 design can be constrained fully by defining the outer diameter of the tube, maximum thickness, minimum thickness, and the grading function which control the variation of thickness between the maximum and minimum values. A non-linear power law equation was used to represent the thickness gradient function $t_{f}(\theta)$ as function of the angular distance $(\theta)$ and grading exponent $(\mathrm{k})$ as shown in Eq. 6

$$
t_{f}(\theta)=t_{\text {max }}-\left(t_{\text {max }}-t_{\text {min }}\right) \times\left(\frac{\theta}{\theta_{m}}\right)^{k}
$$

where $\theta$ is the angular distance from the horizontal axis, $t_{\max }$ is the maximum thickness, $t_{\min }$ is the minimum thickness, $\theta_{m}$ denotes the total gradient angle and it is equal to $45^{\circ}$ in FGT1 design, and $\mathrm{k}$ is the grading exponent which varies between 0.5 and 2. Figure 9 explains the main geometrical parameters of the FGT1 design. 


\subsection{Multi-objective design optimisation framework}

Generally, one of the major challenges in designing a crashworthy structure is to select geometrical and material parameters that can satisfy conflicting crashworthiness design requirements and this can only be achieved via adopting multi-objective optimisation technique.

The general mathematical equation of multi-objective crashworthiness optimisation problem is presented in Eq. 7

$$
\left\{\begin{array}{cc}
\text { Minimise } & f(x)=\left[f_{1}(x), f_{2}(x), \ldots, f_{i}(x)\right] \\
\text { s.t } & x^{l} \leq x \leq x^{u}
\end{array}\right.
$$

where $\mathrm{x}=\left(\mathrm{x}_{1}, \mathrm{x}_{2}, \ldots, \mathrm{x}_{\mathrm{k}}\right)$ is the vector of $\mathrm{k}$ design variables with $x^{l}$ and $x^{u}$ as their lower and upper bounds. The design variables (x) can be either material, geometrical, or loading parameters. $f(x)$ is the objective function which contains one or more of the crashworthiness responses, such as MCF, SEA, PCF and so on. For the crashworthiness responses, it is very hard to derive the objective function analytically as the structure normally exhibits nonlinear mechanical behaviour during the crushing process as a result of large deformation. Thus, surrogate modelling technique is adopted to establish statistical-based models, known as meta-models, which relate the design variables and design responses together and can be used in the optimisation algorithm. Generating such models requires effective sampling technique to represent the design space by an adequate number of design points. Factorial, Box-Behnken design (BBD), central-composite design (CCD), D-optimal, Latin hypercube sampling (LHS) are all examples of design sampling techniques. The fitting accuracy of the developed meta-models is normally inspected using different statistical measures such as R-squared, adjusted and predicted R-squared, and Adeq Precision.

Among the different solution methods, desirability approach, also known as cost objective function, was selected to solve the above multiobjective optimisation problem. This approach seeks the solution for the optimisation problem with multiple objectives by formulating a desirability function which combines all multiple responses into a single non-dimension objective function, thus converting the multi-objective optimisation problem into a single objective problem. This desirability function takes a value between 0 and 1 and the optimal solution is the one with the greatest desirability $[4,53]$. The crashworthiness multi-objective design optimisation framework is illustrated in Figure 10.

\subsection{Metamodeling}

The factorial design method was used as a sampling technique to generate the different combinations of the design variables required for obtaining the meta-model systemically. The geometrical parameterst $t_{\max }, t_{\min }$, and $\mathrm{k}$ were selected as design variables while SEA and PCF were chosen as the crashworthiness responses of interest. The upper and lower bounds of the design 
variables are shown in Table 6. With the aid of the validated FE model described and validated in sections 3.1 and 3.2, numerical crush simulations were conducted for the Ti-FGT1 tubes with different geometrical factors as determined via the sampling technique and the crashworthiness responses were extracted. The different combinations of the geometrical parameters, i.e. design variables, along with the calculated crashworthiness metrics, i.e. design responses, are summarised in the design matrix shown in Table 7. It should be noted that all the tubes representing the design points have the same outer diameter of $100 \mathrm{~mm}$ and the SEA and PCF responses were calculated at CDE of $40 \%$ selected based on the experimental observation presented in sections 2.5.1 and 2.5.2 which showed that the structural failure of Ti-FGT1 occurs at CDE greater than $40 \%$.

Following the calculations of the crashworthiness metrics, the meta-models were established for the crashworthiness responses where their statistical adequacies were verified via analysis of variance (ANOVA) approach which employs various statistical measures to inspect the statistical significance of the models. The obtained meta-models for SEA and PCF in terms of the geometrical parameters are shown in equations 8 and 9 , respectively

$$
\begin{gathered}
(S E A)^{0.58}=\left(9.919 \times 10^{-3}\right)-\left(1.331 \times 10^{-3}\right) t_{\max }-\left(3.588 \times 10^{-4}\right) t_{\min }-\left(1.047 \times 10^{-3}\right) k \\
(P C F)^{0.59}=(0.015176)-\left(9.453 \times 10^{-4}\right) t_{\max }-\left(2.359 \times 10^{-3}\right) t_{\min }-\left(2.344 \times 10^{-3}\right) k+\left(1.141 \times 10^{-4}\right) t_{\max } \times t_{\max } \\
-\left(1.435 \times 10^{-4}\right) t_{\max } \times k+\left(8.1079 \times 10^{-4}\right) t_{\min } \times k
\end{gathered}
$$

The statistical significance indicators for the aforementioned meta-models of SEA and PCF are presented in Table 8. As listed, the developed meta-models exhibit very high R-squared (coefficient of determination) values and they also demonstrate an excellent agreement between the predicted $\mathrm{R}$-squared and adjusted R-squared. The adequate precision ratio, which compares the range of the predicted values at the design points to the average prediction error, was also used as adequacy and significance measure of the developed meta-models. The adequate precision ratios of all metamodels are greater than 4 indicating that the models have minimal noise and thus they can be used to navigate the whole design space.

The aforementioned statistical measurements prove that the developed SEA and PCF metamodels, as presented in Equations 8 and 9, are sufficiently accurate and can be adopted in the parametric and design optimisation analysis.

\subsection{Numerical and optimisation results}

\subsubsection{Plastic strains and stress analysis}


The created FE models were used to analyse the plastic strains and stresses in the tubes to provide further insights on the advantages of adopting the FGT concept in the laterally loaded structures. In order to provide a valid comparison, the simulated UT and FGT1 tubes were crushed up to the same CDE of $40 \%$. Figure 11 (a) shows the equivalent plastic strains distributions in the UT and FGT1 tubes as extracted from the numerical simulations. The plastic strain is a key response in the crashworthiness design as it provides an idea on the volume of the structure that undergoes permanent plastic deformation. In the UT tube, the maximum plastic strain region is located along the horizontal axis of the tube with a maximum magnitude of 0.079. For the FGT1 design, the maximum effective plastic strain is 0.048 and it was located in the regions of minimum thicknesses. By comparing the plastic strains in FGT1 and UT tubes, it is clear that a greater volume of FGT1 tube undergoes plastic deformation and this is indicated by the smaller blue colour regions, i.e. zones with zero plastic strains, in this design compared to those observed in the UT design. This can be considered as the most important advantage of the FGT1 design where it allows a greater volume of the tube to yield and contribute in the energy dissipation process and therefore FGT1 can be considered to be more attractive for crashworthiness applications. This trend is also confirmed by the von misses stress distributions shown in Figure 11 (b) which shows that the FGT1 design exhibits more uniform stress distributions than the UT design with stress values for the majority of its volume exceeding the yield stress. The maximum stress observed in FGT1 design is $1456 \mathrm{MPa}$ which is slightly greater than the maximum stress of UT design.

\subsubsection{Parametric analysis}

The meta-models developed in section 3.5 are used in the subsequent parametric analysis to understand the influence of the geometrical parameters on the crashworthiness responses.

\subsubsection{Effect of design variables on SEA}

Figure 12 illustrates two 3D surface plots for the variation of the SEA with the maximum thickness and gradient exponent at the extreme values of the minimum thickness. It can be seen that SEA increases by increasing all the geometrical parameters, i.e. $t_{\max }, t_{\min }$, and $\mathrm{k}$. This trend can be attributed to the fact that increasing the geometrical parameters leads to increase in the mass of the tube and this means that there is more material in the structure to deform plastically and absorbs energy. Also, Figure 12 reveals that the influence of $t_{\min }$ on SEA response is less than the influence of other variables. For example, when $\mathrm{t}_{\max }$ and $\mathrm{k}$ are at their upper levels, increasing $\mathrm{t}_{\min }$ from the lower value to the upper value, will only increase SEA by $2.1 \%$. Similarly, when $\mathrm{t}_{\min }$ and $\mathrm{k}$ are at their upper levels, increasing $\mathrm{t}_{\max }$ from $5 \mathrm{~mm}$ to $6 \mathrm{~mm}$ will increase SEA by approximately $27 \%$ which clearly shows the higher influence of $t_{\max }$ on SEA compared to $t_{\min }$. This behaviour is expected based on the numerical results presented earlier which show that the amount of the 
absorbed energy is dominated by the plastic zone which is mainly localised around the maximum thickness region.

The greatest SEA can be obtained by a tube with $t_{\max }$ of $6 \mathrm{~mm}, \mathrm{t}_{\min }$ of $3 \mathrm{~mm}$, and $\mathrm{k}$ of 2 which is approximately $164 \%$ higher than the SEA offered by the tube with $t_{\max }$ of $4 \mathrm{~mm}, \mathrm{t}_{\min }$ of $2 \mathrm{~mm}$, and $\mathrm{k}$ of 0.5 .

\subsubsection{Effect of design variables on PCF}

The variation of PCF with the geometrical parameters is presented in Figure 13 including two surface plots for $t_{\min }$ of $2 \mathrm{~mm}$ and $3 \mathrm{~mm}$, respectively. It is evident from these plots that PCF increases as $t_{\max }, t_{\min }$, and $\mathrm{k}$ increases. This is due to the fact that increasing the geometrical parameters of the tube will increase its mass which in turn will increase its lateral stiffness and hence a greater force will be resulted during its crushing. The smallest value of PCF, which corresponds to design variables of $t_{\max }=4 \mathrm{~mm}, \mathrm{t}_{\min }=2 \mathrm{~mm}$, and $\mathrm{k}=0.5$, is approximately $76 \%$ less than the largest value observed at the design variables of $t_{\max }=6 \mathrm{~mm}, \mathrm{t}_{\min }=3 \mathrm{~mm}$, and $\mathrm{k}=2$. The PCF response, as shown in Figure 13, is influenced by the interactions between the various geometrical parameters of the tube. The interaction effects mean that the influence of one parameter on PCF depends on the setting of the other parameters. Such interactions can be inferred via the terms that contain more than one design variables in the meta-model equation of PCF. For example, the influence of $\mathrm{k}$ on PCF is more profound when $t_{\min }$ is smaller. When $t_{\max }=4 \mathrm{~mm}$ and $t_{\min }=2$ $\mathrm{mm}$, increasing $\mathrm{k}$ from 0.5 to 2 yields an increase of $75 \%$ in PCF. However, this increase becomes only $27 \%$ when $t_{\min }$ increases to $3 \mathrm{~mm}$. Similarly, $t_{\max }$ has a greater influence on PCF in the tubes with bigger gradient exponent. When $t_{\min }$ equals to $3 \mathrm{~mm}$, increasing $t_{\text {max }}$ from $4 \mathrm{~mm}$ to $6 \mathrm{~mm}$ leads to an increase of $116 \%$ in PCF for k of 2 against an increase of $62 \%$ for $k$ of 0.5 .

\subsubsection{Design optimisation of FGT1}

It was shown in the previous section that the geometrical parameters of the FGT1 have a great influence on its responses under the lateral loading and thus it is vital to determine the optimal combination of the geometrical parameters that yield the most desirable crashworthiness responses. SEA and PCF, as key crashworthiness metrics, were considered in many crashworthiness optimisation studies [51,54]. Within the context of good lightweight crashworthiness design, the protective structure should dissipate as high as possible SEA without increasing PCF to high levels as extremely high PCF may cause severe injuries or even death to the occupants [1]. Thus, the multi-objectives crashworthiness optimisation scheme of this study aims to maximise SEA and minimize PCF within the range of the geometrical parameters as shown in Table 6. The metamodels of SEA and PCF developed in section 3.5 are used in the optimisation formula presented in equation 10 


$$
\left\{\begin{array}{cc}
\text { Maxmize SEA } & =f\left(t_{\text {max }}, t_{\text {min }}, k\right) \\
\text { Minmize PCF } & =f\left(t_{\max }, t_{\text {min }}, k\right) \\
\text { s. } t & 4 \leq t_{\max } \leq 6 \\
\text { s.t } & 2 \leq t_{\min } \leq 3 \\
\text { s.t } & 0.5 \leq \mathrm{k} \leq 2
\end{array}\right.
$$

Desirability approach was employed in this study to solve the above multi-objective optimisation formula due to its simplicity, relatively low computational cost and rapid convergence [4,5,55]. Equal importance and weighting were assigned for both design responses. Figure 14 displays contour plots of the desirability objective as a function of $\mathrm{t}_{\max }$ and $\mathrm{k}$ at the upper and lower values of $t_{\min }$. The greatest desirability of 0.5728 was obtained at geometrical parameters of $t_{\max }=$ $6 \mathrm{~mm}, \mathrm{t}_{\min }=2 \mathrm{~mm}, \mathrm{k}=1$ indicating that optimal design of FGT1 is the one with maximum $\mathrm{t}_{\max }$, minimum $t_{\text {min }}$, and linear thickness gradient. It is well reported in the literature that maximizing SEA and minimizing PCF are always two competing objectives and this is also evidenced from the parametric analysis results presented in the previous section. The optimal thickness gradient parameters, determined by the optimisation algorithm, provide a good balance between the two conflicting crashworthiness design objectives allowing the desirability function to reach its maximum value. As it can be seen from Figure 14, increasing k to 2 drops the desirability to 0.183 while reducing $\mathrm{k}$ to 0.5 decreases the desirability to 0.537 . Also, reducing $\mathrm{t}_{\max }$ to $4 \mathrm{~mm}$ or increasing $\mathrm{t}_{\min }$ to $3 \mathrm{~mm}$ decreases the desirability to 0.298 and 0.523 , respectively. Thus, it can be reported that the functionally graded thickness tubes with linear thickness gradient are preferred for use as energy-absorbing structures under lateral loading. A numerical crush test was conducted via FE model to validate the optimisation results as obtained by the desirability approach. The comparisons between the desirability and the FE results are shown in Table 9. It is clear that the percentage errors for both crashworthiness metrics; i.e. SEA and PCF, are small and within acceptable range which in turn confirms the validity of the obtained optimisation results. The deformation history of the optimal configuration of Ti-FGT1 is shown in Figure 15.

\section{Conclusion}

In this paper, new designs of circular tubes with perimetrical thickness gradient were considered for lateral deformation mode. SLM was used to manufacture the tubes from titanium (Ti6Al4V) and aluminium (AlSi10Mg) bulk powder and crush tests were conducted on the different specimens to evaluate their crashworthiness performance.

The FGT titanium tube, denoted as Ti-FGT1, with maximum thickness along the horizontal and vertical axes; and minimum thickness located at an angle of $45^{\circ}$ with respect to the horizontal axis was found to outperform all other FGT and UT designs in both material groups in terms of energy absorption metrics. This FGT design can maximise the amount of material within the structure that 
undergoes plastic deformation and absorb the greatest amount of energy. It yielded 79\% and 102\% greater SEA than its Ti-UT and AL-FGT1 counterparts, respectively. It also recorded the highest CDE and third-highest CFE among all other tubes.

To further reveal detailed design guidelines of the best performing tube, FE simulations, surrogate modelling, and multi-objective optimisation tools were integrated to conduct the parametric analysis and to find the optimal design. Significant influences were observed for the geometrical parameters on the responses of the Ti-FGT1 tube where both SEA and PCF increased by increasing the maximum and minimum thicknesses as well as the thickness gradient exponent. Furthermore, the optimisation analysis indicated that selecting a linear thickness gradient along with the highest possible maximum thickness and lowest possible minimum thickness can satisfy best the crashworthiness design requirements of achieving maximum SEA and minimum PCF.

\section{Acknowledgement}

This work is funded by the University of Wolverhampton through early research award scheme (ERAS).

\section{References}

[1] A. Baroutaji, M. Sajjia, A.-G.G. Olabi, On the crashworthiness performance of thin-walled energy absorbers: Recent advances and future developments, Thin-Walled Struct. 118 (2017) 137-163. doi:10.1016/j.tws.2017.05.018.

[2] A.A.A. Alghamdi, Collapsible impact energy absorbers: an overview, Thin-Walled Struct. 39 (2001) 189-213. doi:10.1016/S0263-8231(00)00048-3.

[3] A.G. Olabi, E. Morris, M.S.J. Hashmi, Metallic tube type energy absorbers: A synopsis, Thin-Walled Struct. 45 (2007) 706-726. doi:10.1016/j.tws.2007.05.003.

[4] A. Baroutaji, M.D. Gilchrist, D. Smyth, A.G. Olabi, Crush analysis and multi-objective optimization design for circular tube under quasi-static lateral loading, Thin-Walled Struct. 86 (2015) 121-131. doi:10.1016/j.tws.2014.08.018.

[5] A. Baroutaji, E. Morris, A.G. Olabi, Quasi-static response and multi-objective crashworthiness optimization of oblong tube under lateral loading, Thin-Walled Struct. 82 (2014) 262-277. doi:10.1016/j.tws.2014.03.012.

[6] T. Tang, W. Zhang, H. Yin, H. Wang, Crushing analysis of thin-walled beams with various section geometries under lateral impact, Thin-Walled Struct. 102 (2016) 43-57. doi:10.1016/j.tws.2016.01.017.

[7] Z. Li, H. Yang, X. Hu, J. Wei, Z. Han, Experimental study on the crush behavior and energyabsorption ability of circular magnesium thin-walled tubes and the comparison with 
aluminum tubes, Eng. Struct. 164 (2018) 1-13. doi:10.1016/J.ENGSTRUCT.2018.02.083.

[8] A. Niknejad, S.M. Elahi, S.A. Elahi, S.A. Elahi, Theoretical and experimental study on the flattening deformation of the rectangular brazen and aluminum columns, Arch. Civ. Mech. Eng. 13 (2013) 449-464. doi:10.1016/j.acme.2013.04.008.

[9] S. Li, X. Guo, Q. Li, G. Sun, On lateral crashworthiness of aluminum/composite hybrid structures, Compos. Struct. 245 (2020) 112334. doi:10.1016/j.compstruct.2020.112334.

[10] A. Baroutaji, M.D. Gilchrist, A.G. Olabi, Quasi-static, impact and energy absorption of internally nested tubes subjected to lateral loading, Thin-Walled Struct. 98 (2016) 337-350. doi:10.1016/j.tws.2015.10.001.

[11] A. Baroutaji, A.G. Olabi, Lateral collapse of short-length sandwich tubes compressed by different indenters and exposed to external constraints, Materwiss. Werksttech. 45 (2014) n/a-n/a. doi:10.1002/mawe.201400236.

[12] J. Fang, Y. Gao, G. Sun, G. Zheng, Q. Li, Dynamic crashing behavior of new extrudable multi-cell tubes with a functionally graded thickness, Int. J. Mech. Sci. 103 (2015) 63-73. doi:10.1016/j.ijmecsci.2015.08.029.

[13] L. Cui, S. Kiernan, M.D. Gilchrist, Designing the energy absorption capacity of functionally graded foam materials, Mater. Sci. Eng. A. 507 (2009) 215-225. doi:10.1016/j.msea.2008.12.011.

[14] X. An, Y. Gao, J. Fang, G. Sun, Q. Li, Crashworthiness design for foam-filled thin-walled structures with functionally lateral graded thickness sheets, Thin-Walled Struct. 91 (2015) 63-71. doi:10.1016/j.tws.2015.01.011.

[15] F. Xu, X. Zhang, H. Zhang, A review on functionally graded structures and materials for energy absorption, Eng. Struct. 171 (2018) 309-325. doi:10.1016/J.ENGSTRUCT.2018.05.094.

[16] T. Børvik, O.S. Hopperstad, a Reyes, M. Langseth, G. Solomos, T. Dyngeland, Empty and foam-filled circular aluminium tubes subjected to axial and oblique quasistatic loading, Int. J. Crashworthiness. 8 (2003) 481-494. doi:10.1533/ijcr.2003.0254.

[17] A. Niknejad, S.A. Elahi, G.H. Liaghat, Experimental investigation on the lateral compression in the foam-filled circular tubes, Mater. Des. 36 (2012) 24-34. doi:10.1016/j.matdes.2011.10.047.

[18] H. Nikkhah, A. Baroutaji, Z. Kazanc1, A. Arjunan, Evaluation of crushing and energy absorption characteristics of bio-inspired nested structures, Thin-Walled Struct. 148 (2020) 106615.

[19] T.N. Tran, D.H. Le, A. Baroutaji, Theoretical and numerical crush analysis of multi-stage nested aluminium alloy tubular structures under axial impact loading, Eng. Struct. 182 (2019) 
39-50. doi:10.1016/j.engstruct.2018.12.072.

[20] S.E. Alkhatib, F. Tarlochan, A. Eyvazian, Collapse behavior of thin-walled corrugated tapered tubes, Eng. Struct. 150 (2017) 674-692. doi:10.1016/J.ENGSTRUCT.2017.07.081.

[21] T. Tran, S. Hou, X. Han, N. Nguyen, M. Chau, Theoretical prediction and crashworthiness optimization of multi-cell square tubes under oblique impact loading, Int. J. Mech. Sci. 89 (2014) 177-193. doi:10.1016/j.ijmecsci.2014.08.027.

[22] J. Fang, Y. Gao, G. Sun, N. Qiu, Q. Li, On design of multi-cell tubes under axial and oblique impact loads, Thin-Walled Struct. 95 (2015) 115-126. doi:10.1016/j.tws.2015.07.002.

[23] X. Zhang, H. Zhang, Energy absorption of multi-cell stub columns under axial compression, Thin-Walled Struct. 68 (2013) 156-163. doi:10.1016/j.tws.2013.03.014.

[24] X. Zhang, Z. Wen, H. Zhang, Axial crushing and optimal design of square tubes with graded thickness, Thin-Walled Struct. 84 (2014) 263-274. doi:10.1016/j.tws.2014.07.004.

[25] G. Sun, F. Xu, G. Li, Q. Li, Crashing analysis and multiobjective optimization for thinwalled structures with functionally graded thickness, Int. J. Impact Eng. 64 (2014) 62-74. doi:10.1016/j.ijimpeng.2013.10.004.

[26] J. Zhang, B. Song, Q. Wei, D. Bourell, Y. Shi, A review of selective laser melting of aluminum alloys: Processing, microstructure, property and developing trends, J. Mater. Sci. Technol. 35 (2019) 270-284. doi:10.1016/j.jmst.2018.09.004.

[27] X. Zhang, H. Zhang, Z. Wang, Bending collapse of square tubes with variable thickness, Int. J. Mech. Sci. 106 (2016) 107-116. doi:10.1016/j.ijmecsci.2015.12.006.

[28] F. Xu, X. Wan, Y. Chen, Design optimization of thin-walled circular tubular structures with graded thickness under later impact loading, Int. J. Automot. Technol. 18 (2017) 439-449. doi:10.1007/s 12239-017-0044-2.

[29] C. Baykasoglu, M.T. Cetin, Energy absorption of circular aluminium tubes with functionally graded thickness under axial impact loading, Int. J. Crashworthiness. 20 (2015) 95-106. doi:10.1080/13588265.2014.982269.

[30] G. Sun, T. Pang, G. Zheng, J. Song, Q. Li, On energy absorption of functionally graded tubes under transverse loading, Int. J. Mech. Sci. 115-116 (2016) 465-480. doi:10.1016/j.ijmecsci.2016.06.021.

[31] A. Baykasoğlu, C. Baykasoğlu, Multiple objective crashworthiness optimization of circular tubes with functionally graded thickness via artificial neural networks and genetic algorithms, Proc. Inst. Mech. Eng. Part C J. Mech. Eng. Sci. 231 (2017) 2005-2016. doi:10.1177/0954406215627181.

[32] T. Pang, G. Zheng, J. Fang, D. Ruan, G. Sun, Energy absorption mechanism of axiallyvarying thickness (AVT) multicell thin-walled structures under out-of-plane loading, Eng. 
Struct. 196 (2019) 109130. doi:10.1016/j.engstruct.2019.04.074.

[33] A. Baykasoglu, C. Baykasoglu, Crashworthiness optimization of circular tubes with functionally-graded thickness, Eng. Comput. (Swansea, Wales). 33 (2016) 1560-1585. doi:10.1108/EC-08-2015-0245.

[34] X. Zhang, H. Zhang, Z. Wen, Axial crushing of tapered circular tubes with graded thickness, Int. J. Mech. Sci. 92 (2015) 12-23. doi:10.1016/j.ijmecsci.2014.11.022.

[35] G. Li, Z. Zhang, G. Sun, X. Huang, Q. Li, Comparison of functionally-graded structures under multiple loading angles, Thin-Walled Struct. 94 (2015) 334-347. doi:10.1016/j.tws.2015.04.030.

[36] G. Sun, X. Tian, J. Fang, F. Xu, G. Li, X. Huang, Dynamical bending analysis and optimization design for functionally graded thickness (FGT) tube, Int. J. Impact Eng. 78 (2015) 128-137. doi:10.1016/j.ijimpeng.2014.12.007.

[37] G. Sun, J. Tian, T. Liu, X. Yan, X. Huang, Crashworthiness optimization of automotive parts with tailor rolled blank, Eng. Struct. 169 (2018) 201-215. doi:10.1016/j.engstruct.2018.05.050.

[38] H. Zhang, G. Sun, Z. Xiao, G. Li, Q. Li, Bending characteristics of top-hat structures through tailor rolled blank (TRB) process, Thin-Walled Struct. 123 (2018) 420-440. doi:10.1016/j.tws.2017.10.032.

[39] N.T. Aboulkhair, M. Simonelli, L. Parry, I. Ashcroft, C. Tuck, R. Hague, 3D printing of Aluminium alloys: Additive Manufacturing of Aluminium alloys using selective laser melting, Prog. Mater. Sci. 106 (2019). doi:10.1016/j.pmatsci.2019.100578.

[40] E.O. Olakanmi, R.F. Cochrane, K.W. Dalgarno, A review on selective laser sintering/melting (SLS/SLM) of aluminium alloy powders: Processing, microstructure, and properties, Prog. Mater. Sci. 74 (2015) 401-477. doi:10.1016/j.pmatsci.2015.03.002.

[41] L. Girelli, M. Tocci, M. Gelfi, A. Pola, Study of heat treatment parameters for additively manufactured AlSi10Mg in comparison with corresponding cast alloy, Mater. Sci. Eng. A. 739 (2019) 317-328. doi:10.1016/j.msea.2018.10.026.

[42] E. Zaretsky, A. Stern, N. Frage, Dynamic response of AlSi10Mg alloy fabricated by selective laser melting, Mater. Sci. Eng. A. 688 (2017) 364-370. doi:10.1016/j.msea.2017.02.004.

[43] A. Arjunan, M. Demetriou, A. Baroutaji, C. Wang, Mechanical performance of highly permeable laser melted Ti6Al4V bone scaffolds, J. Mech. Behav. Biomed. Mater. (2020). doi:10.1016/j.jmbbm.2019.103517.

[44] A. Baroutaji, A. Arjunan, A. Niknejad, T. Tran, A.-G. Olabi, Application of Cellular Material in Crashworthiness Applications: An Overview, Ref. Modul. Mater. Sci. Mater. Eng. (2019). doi:10.1016/B978-0-12-803581-8.09268-7. 
[45] A. Arjunan, M. Singh, A. Baroutaji, C. Wang, Additively manufactured AlSi10Mg inherently stable thin and thick-walled lattice with negative Poisson's ratio, Compos. Struct. 247 (2020). doi:10.1016/j.compstruct.2020.112469.

[46] S.E. Alkhatib, M.S. Matar, F. Tarlochan, O. Laban, A.S. Mohamed, N. Alqwasmi, Deformation modes and crashworthiness energy absorption of sinusoidally corrugated tubes manufactured by direct metal laser sintering, Eng. Struct. 201 (2019). doi:10.1016/j.engstruct.2019.109838.

[47] A.S. Mohamed, O. Laban, F. Tarlochan, S.E. Al Khatib, M.S. Matar, E. Mahdi, Experimental analysis of additively manufactured thin-walled heat-treated circular tubes with slits using AlSi10Mg alloy by quasi-static axial crushing test, Thin-Walled Struct. 138 (2019) 404-414. doi:10.1016/j.tws.2019.02.022.

[48] M.M. Osman, M. Shazly, E.A. El-Danaf, P. Jamshidi, M.M. Attallah, Compressive behavior of stretched and composite microlattice metamaterial for energy absorption applications, Compos. Part B Eng. 184 (2020) 107715. doi:10.1016/j.compositesb.2019.107715.

[49] N. Jin, F. Wang, Y. Wang, B. Zhang, H. Cheng, H. Zhang, Failure and energy absorption characteristics of four lattice structures under dynamic loading, Mater. Des. 169 (2019). doi:10.1016/j.matdes.2019.107655.

[50] L. Zhang, S. Feih, S. Daynes, S. Chang, M.Y. Wang, J. Wei, W.F. Lu, Energy absorption characteristics of metallic triply periodic minimal surface sheet structures under compressive loading, Addit. Manuf. 23 (2018) 505-515. doi:10.1016/j.addma.2018.08.007.

[51] H. Nikkhah, A. Baroutaji, A.G. Olabi, Crashworthiness design and optimisation of windowed tubes under axial impact loading, Thin-Walled Struct. 142 (2019) 132-148. doi:10.1016/J.TWS.2019.04.052.

[52] G. Lu, T.X. Yu, Energy Absorption of Structures and Materials, Elsevier, 2003. https://books.google.com/books?hl=en\&lr=\&id=wRSkAgAAQBAJ\&pgis=1 (accessed January 20, 2016).

[53] A. Baroutaji, S. Lenihan, K. Bryan, Compaction analysis and optimisation of convex-faced pharmaceutical tablets using numerical techniques, Particuology. 47 (2019) 10-21. https://www.sciencedirect.com/science/article/pii/S1674200119300392\#bib0090 (accessed April 10, 2019).

[54] T. Tran, A. Baroutaji, Crashworthiness optimal design of multi-cell triangular tubes under axial and oblique impact loading, Eng. Fail. Anal. 93 (2018) 241-256. doi:10.1016/J.ENGFAILANAL.2018.07.003.

[55] A. Baroutaji, M.D. Gilchrist, D. Smyth, A.G. Olabi, Analysis and optimization of sandwich tubes energy absorbers under lateral loading, Int. J. Impact Eng. 82 (2015) 74-88. 
doi:10.1016/j.ijimpeng.2015.01.005.

[56] E.O.S. GmbH - Electro Optical Systems, Material Data Sheet EOS Aluminum AlSi10Mg, (2014).

https://cdn0.scrvt.com/eos/public/8837de942d78d3b3/4e099c3a857fdddca4be9d59fbb1cd74/ EOS_Aluminium_AlSi10Mg_en.pdf.

[57] E.O.S. GmbH - Electro Optical Systems, Material Data Sheet EOS Titanium Ti64 M290, (2017). https://cdn.eos.info/a4eeb73865d54434/5926811b3739/Ti-Ti64_9011-0014_90110039_M290_Material_data_sheet_11-17_en.pdf. 
Figure 1: Geometrical configurations of UT and FGT tubes

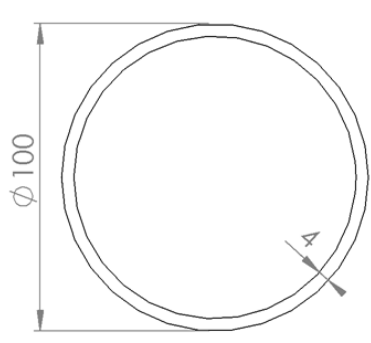

UT

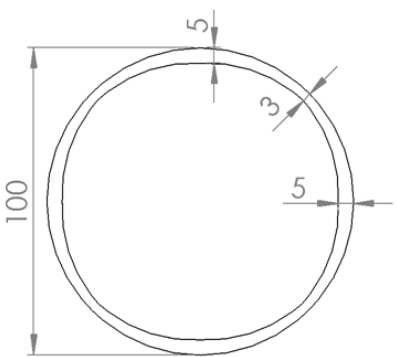

FGT1

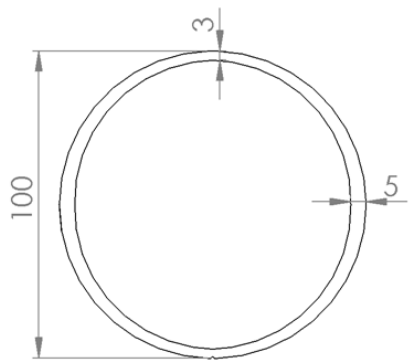

FGT2

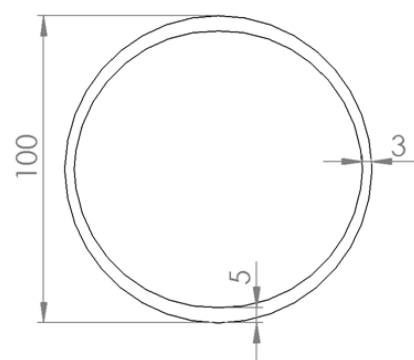

FGT3 

Figure 3: True stress-strain of (a) $\mathrm{Al}$ and (b) Ti materials
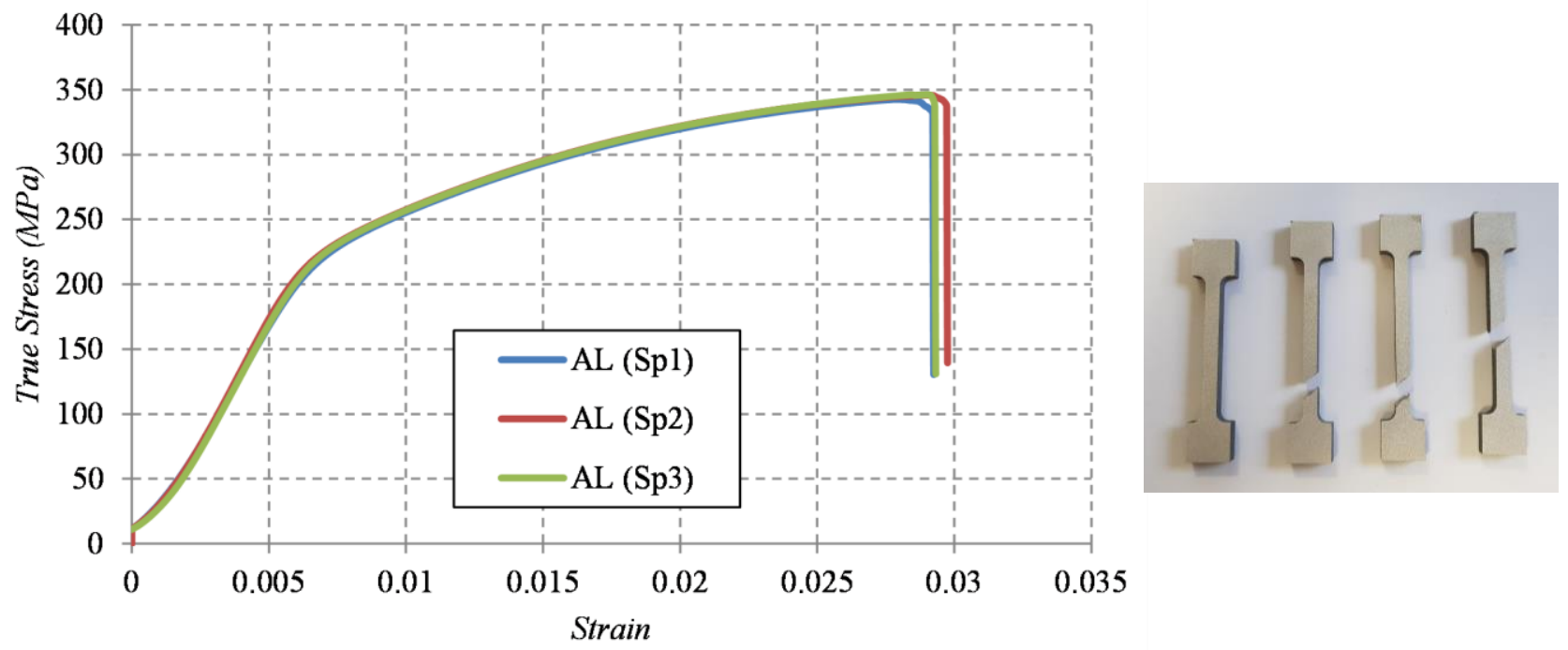

(a)
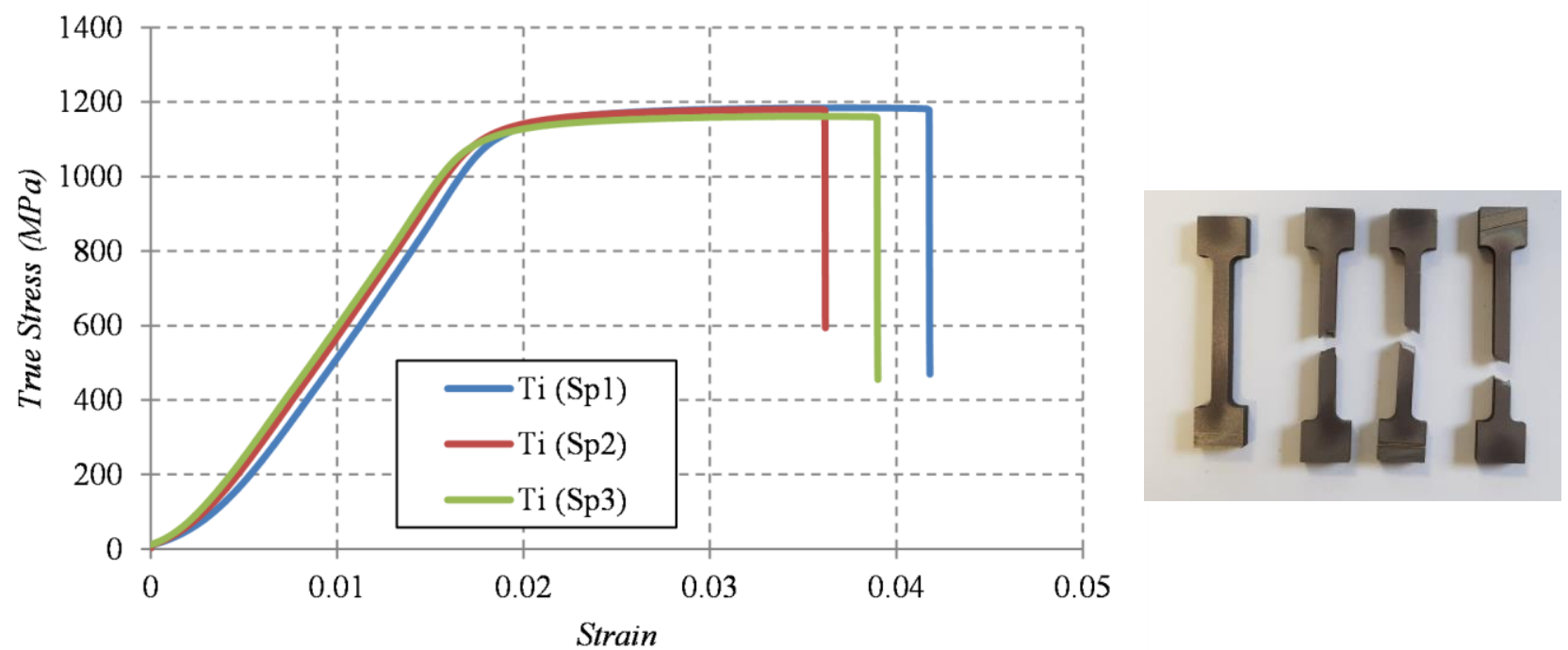

(b) 
Figure 4: Force- displacement responses for (a) $\mathrm{Al}$ and (b) Ti tubes

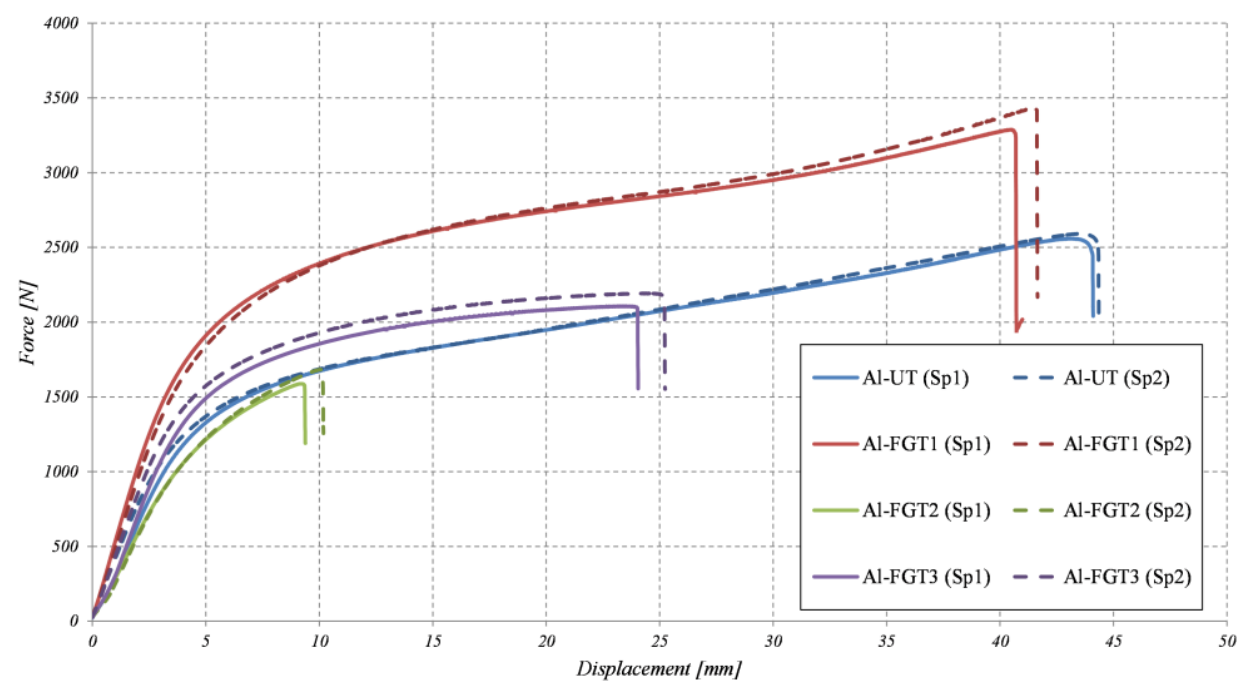

(a)

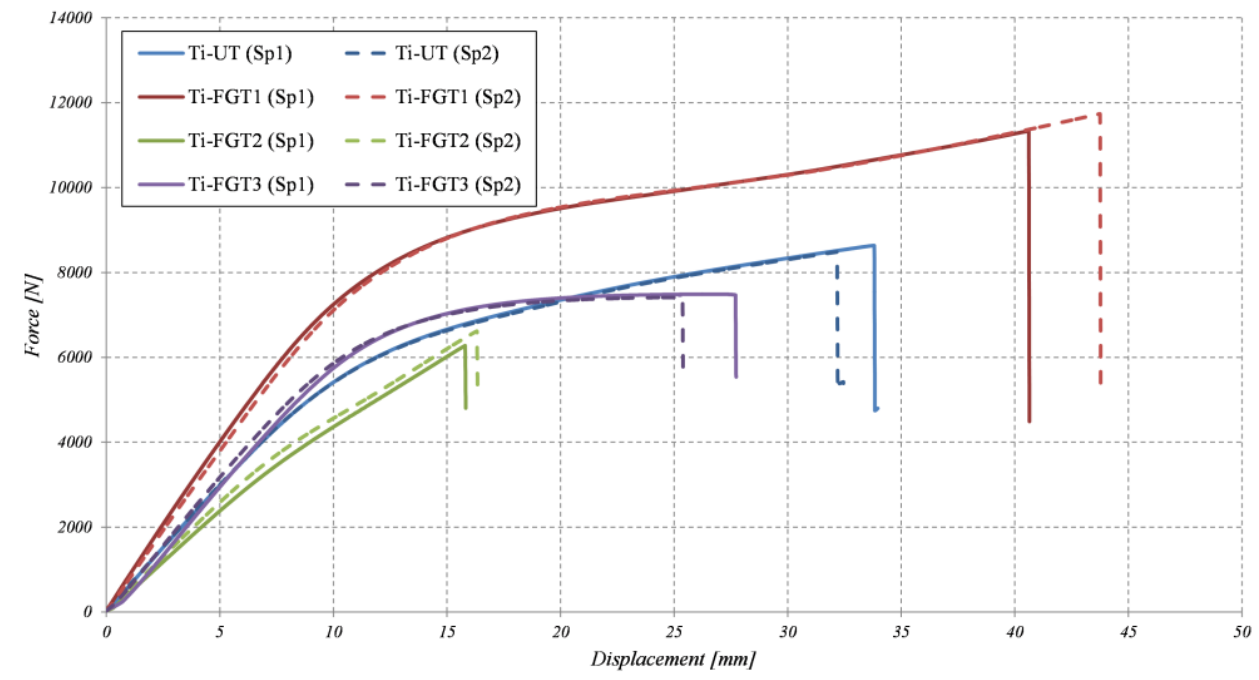

(b) 
Figure 5: Deformation modes of (a) $\mathrm{Al}$ and (b) Ti tubes

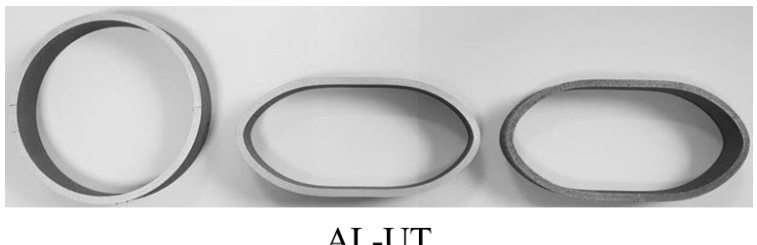

AL-UT

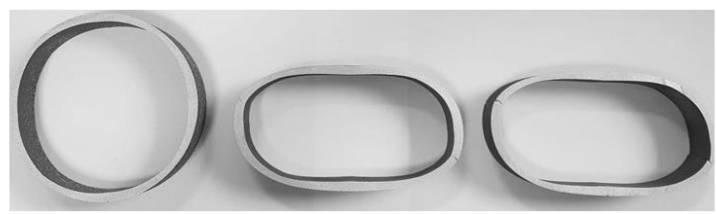

AL-FGT1

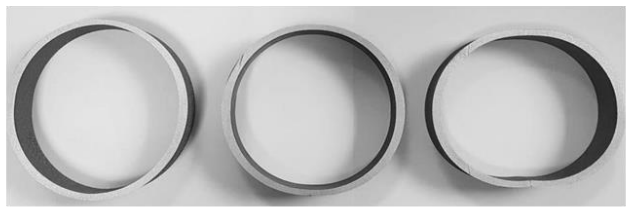

AL-FGT2

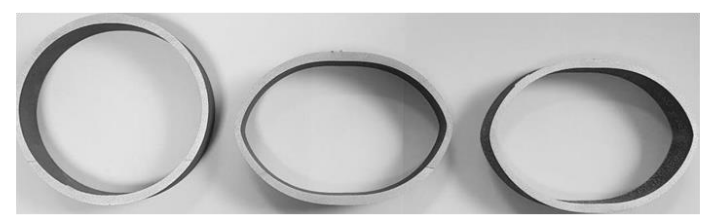

AL-FGT3

(a)

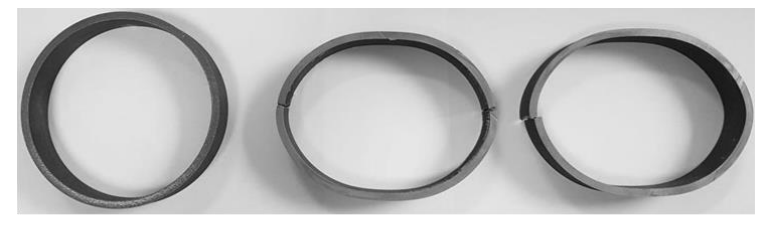

Ti-UT

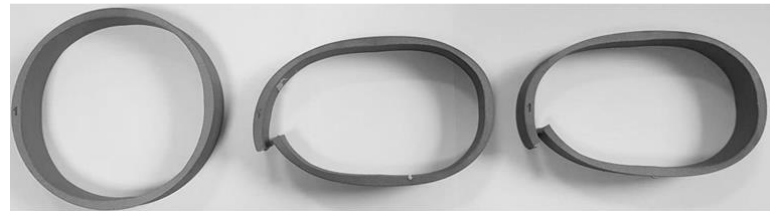

Ti-FGT1

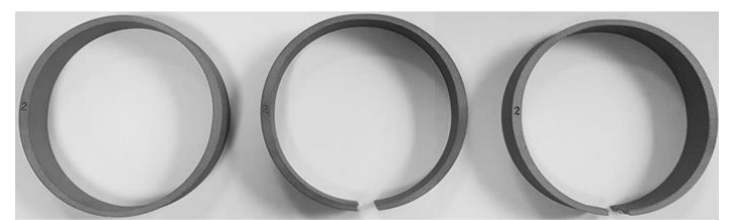

Ti-FGT2

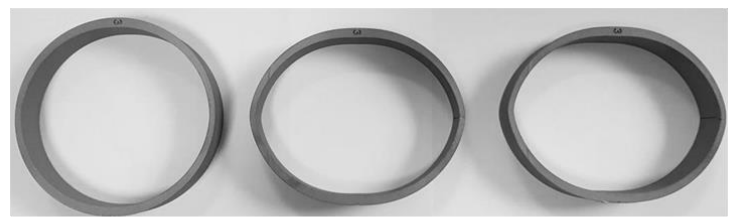

Ti-FGT3

(b) 
Figure 6: Crashworthiness metrics of Al and Ti tubes with different UT and FGT designs: (a) SEA; (b) CFE; (d) CDE

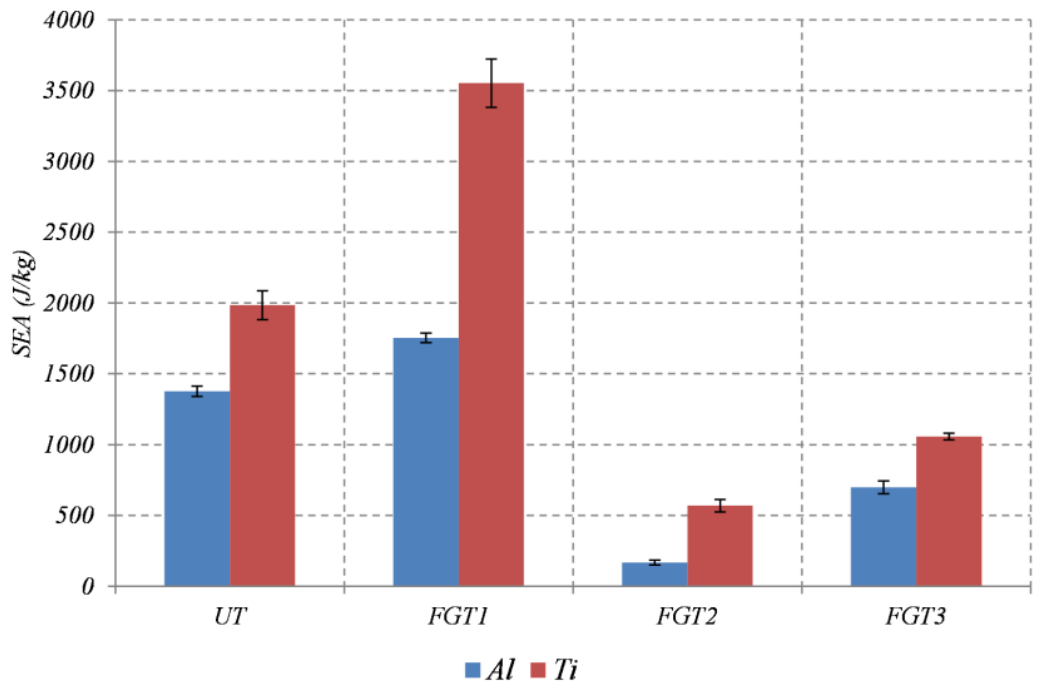

(a)

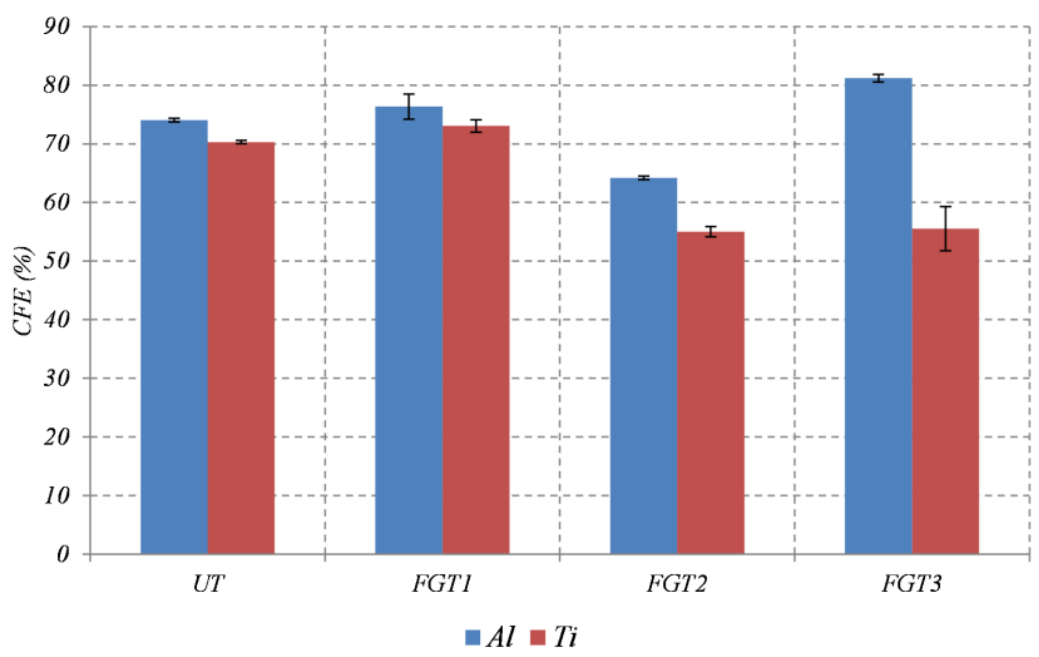

(b)

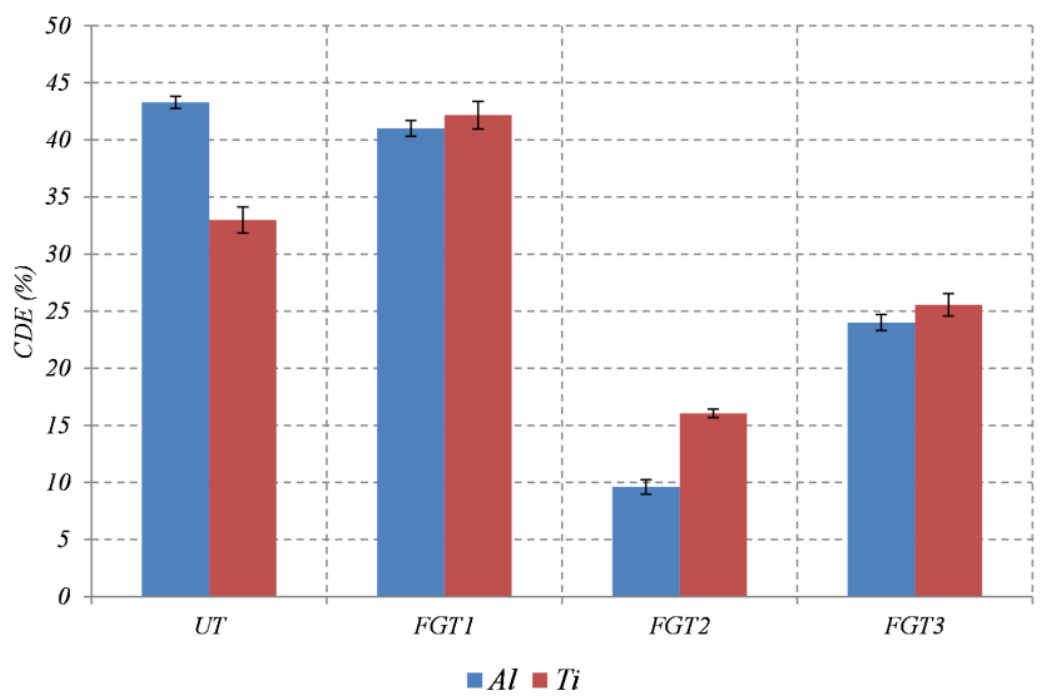

(c) 
Figure 7: Illustration of finite element model of UT tube under lateral loading showing the main component and the boundary conditions

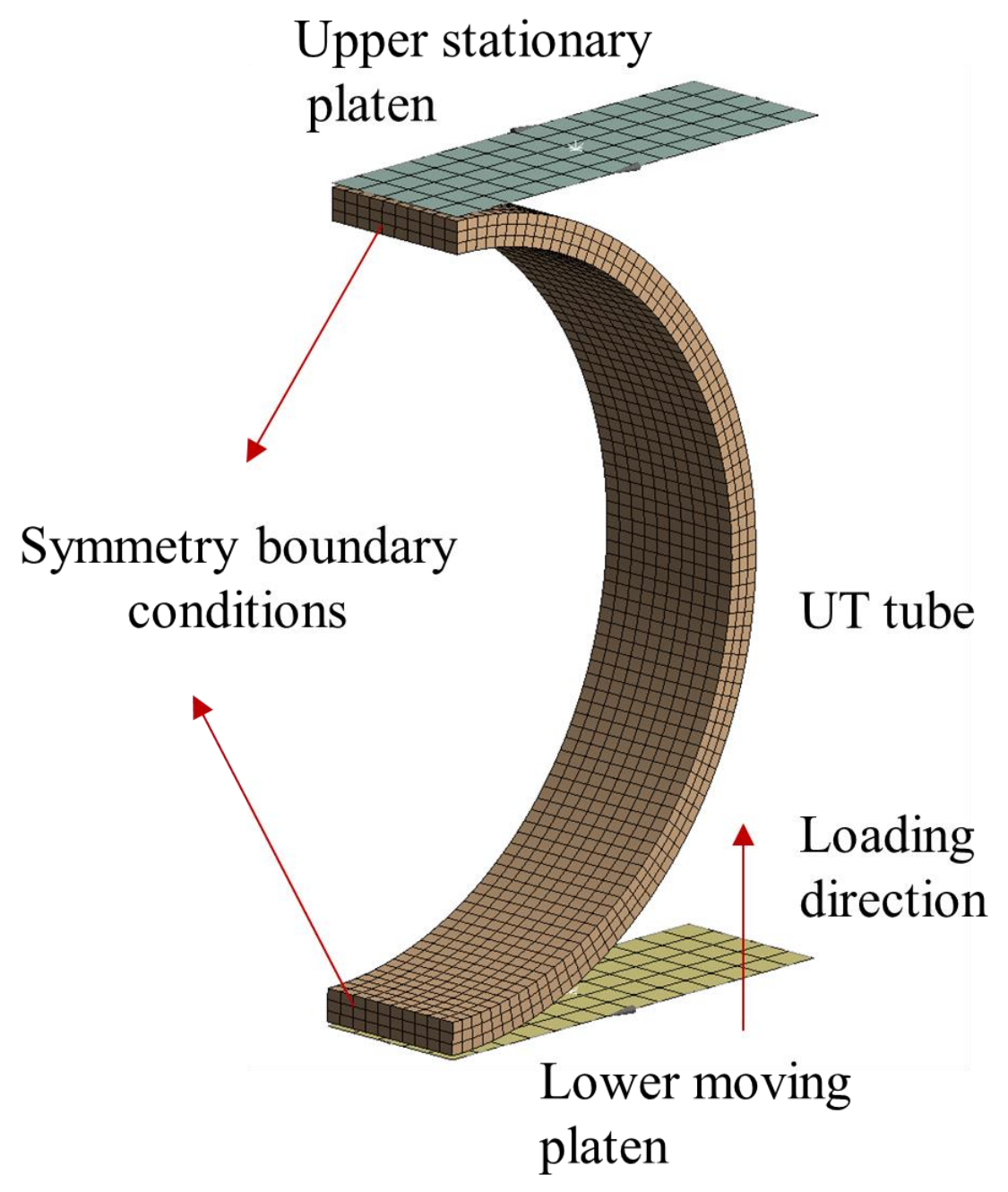


Figure 8: Comparison of numerical predictions and experimental measurements for Ti tubes with (a) UT; (b) FGT1 design
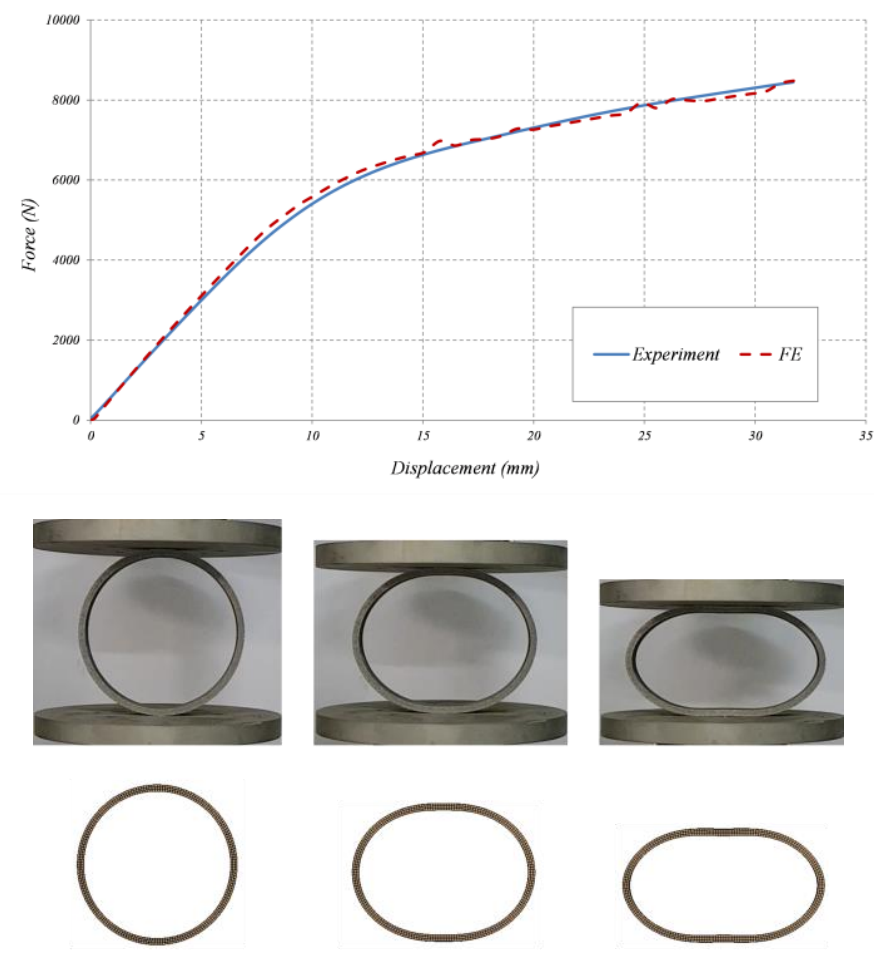

$\delta=0 \mathrm{~mm}$

$\delta=16 \mathrm{~mm}$

$\delta=32 \mathrm{~mm}$

(a)
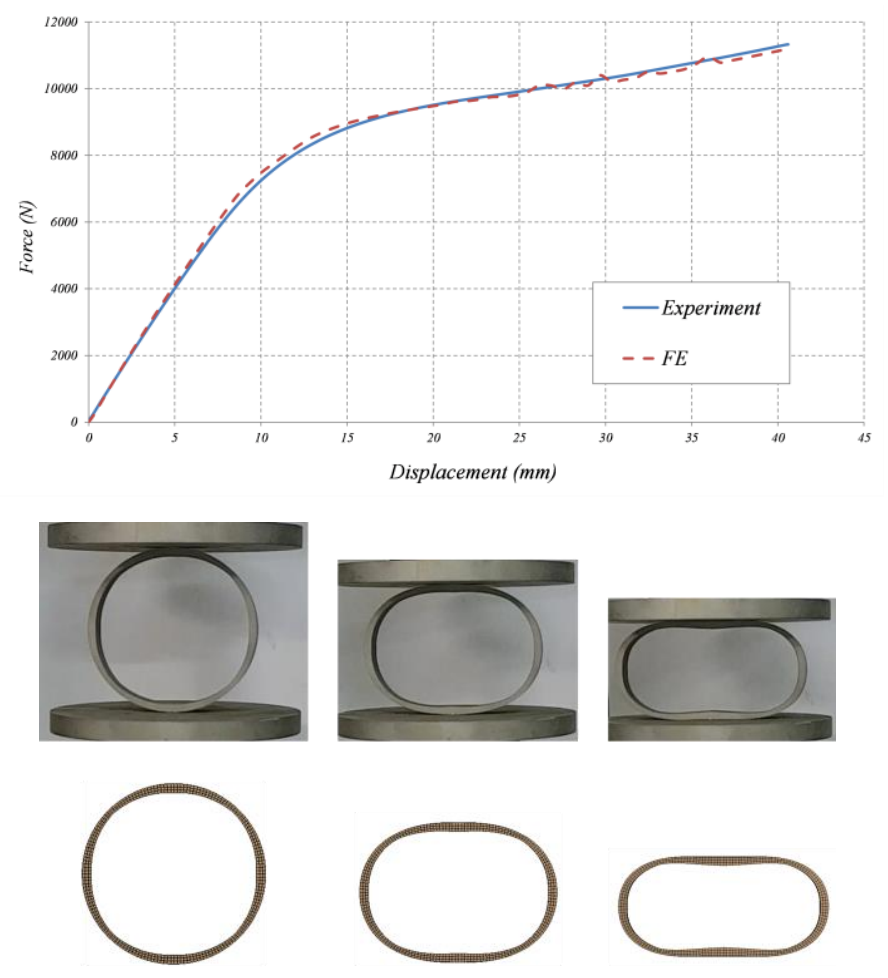

$\delta=0 \mathrm{~mm}$

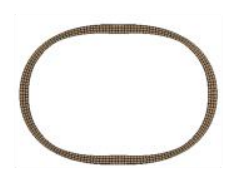

$\delta=20 \mathrm{~mm}$

(b)

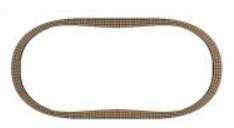

$\delta=40 \mathrm{~mm}$ 
Figure 9: Explanation of geometrical parameters of FGT1 design

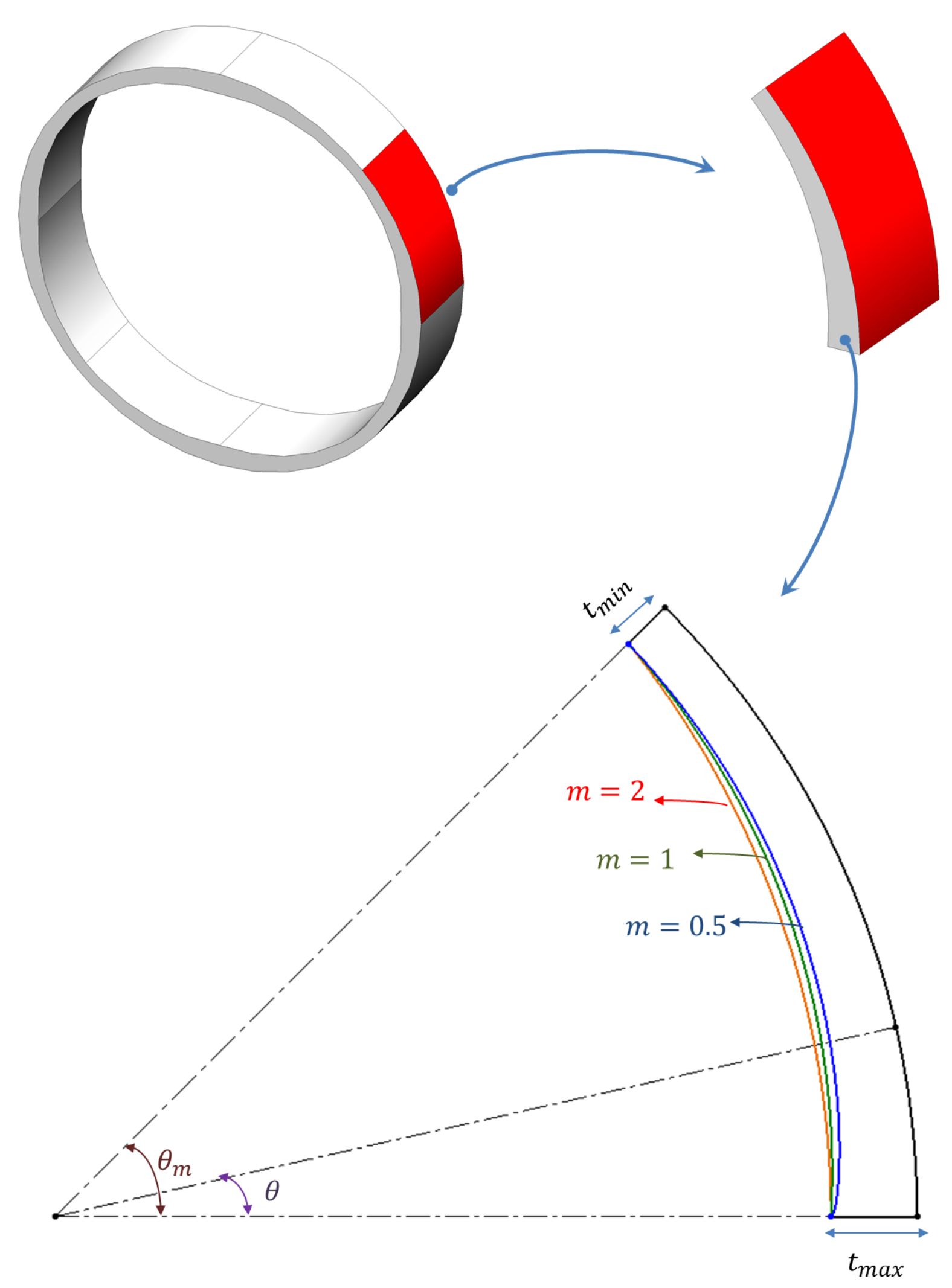


Figure 10: Flowchart explaining the multi-objective framework used in this paper

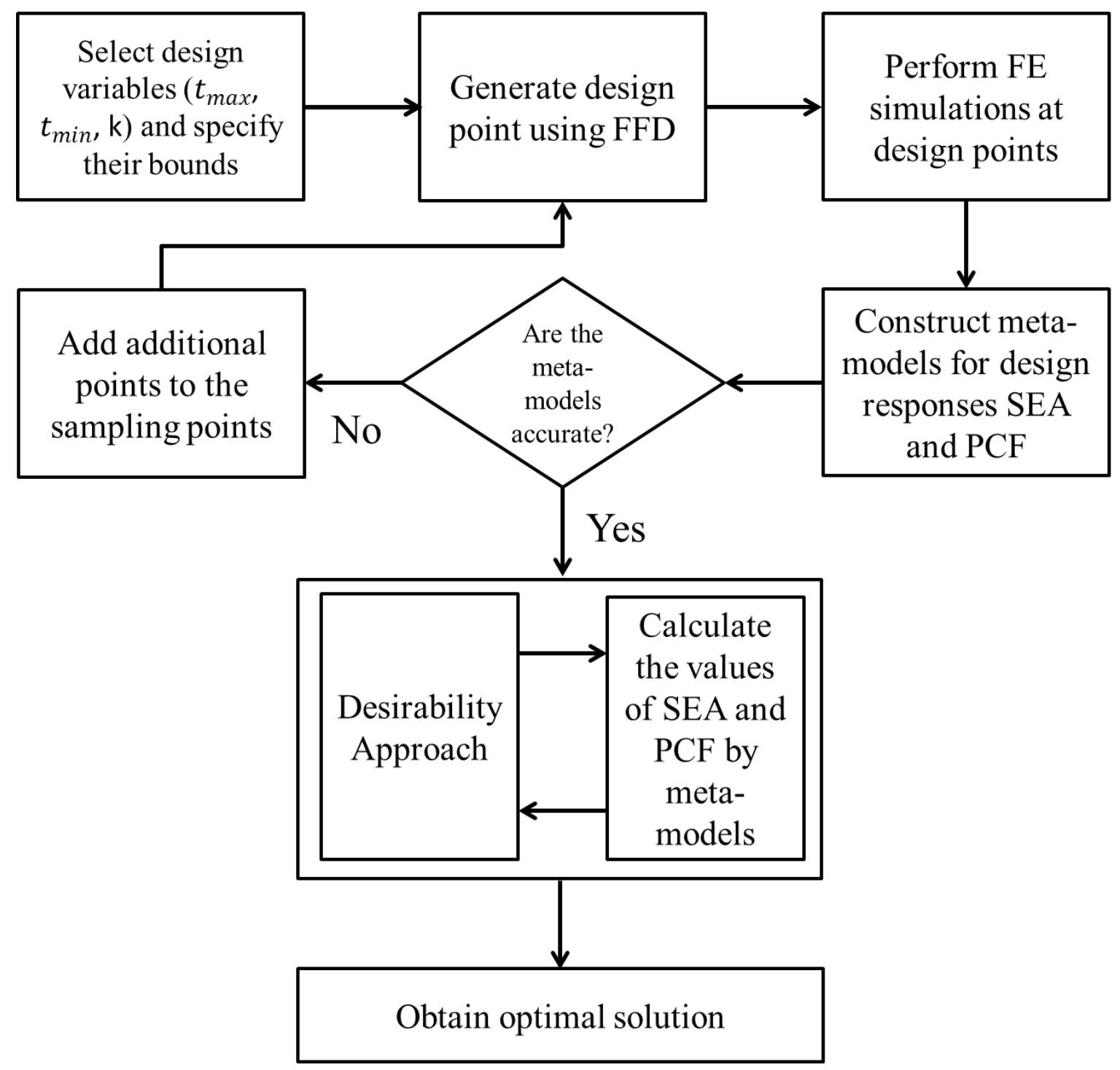


Figure 11: (a) equivalent plastic strain and (b) von misses stress distributions at a CDE of $40 \%$ in UT and

\section{FGT1 designs}
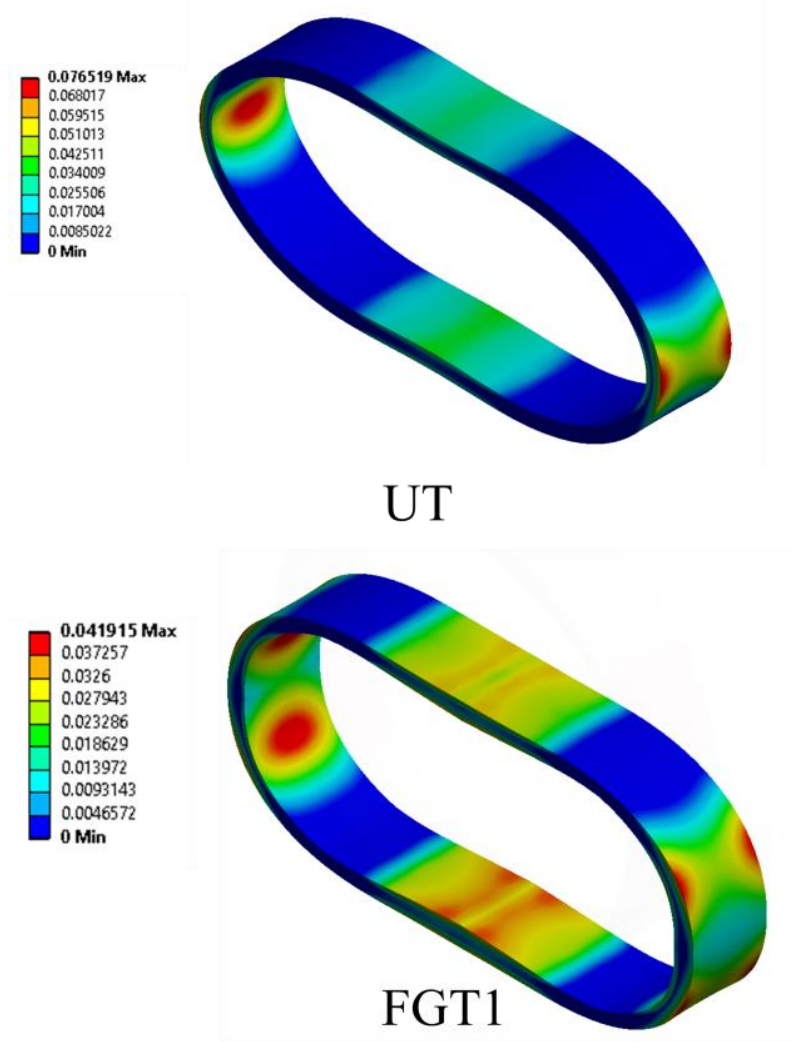

(a)
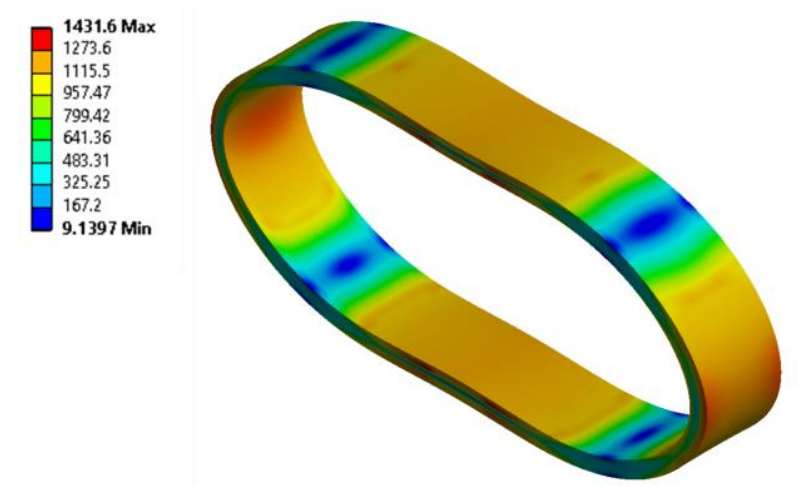

UT
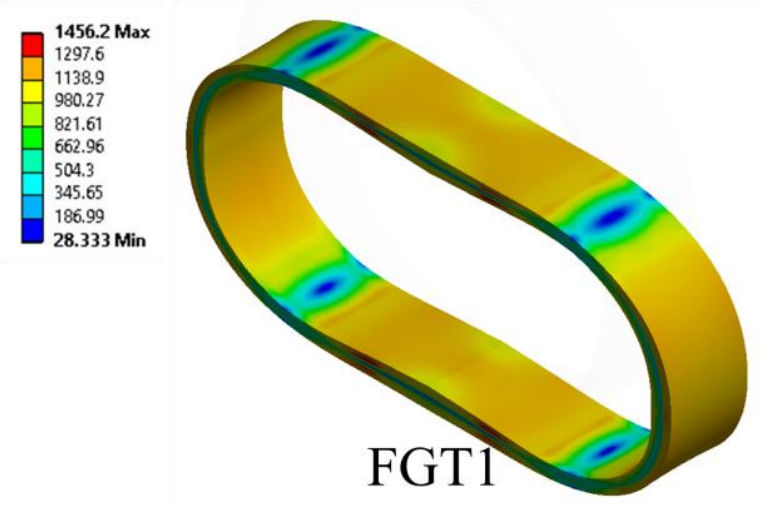

(b) 
Figure 12: Surface plots showing the variation of SEA with the geometrical parameters of FGT1 design
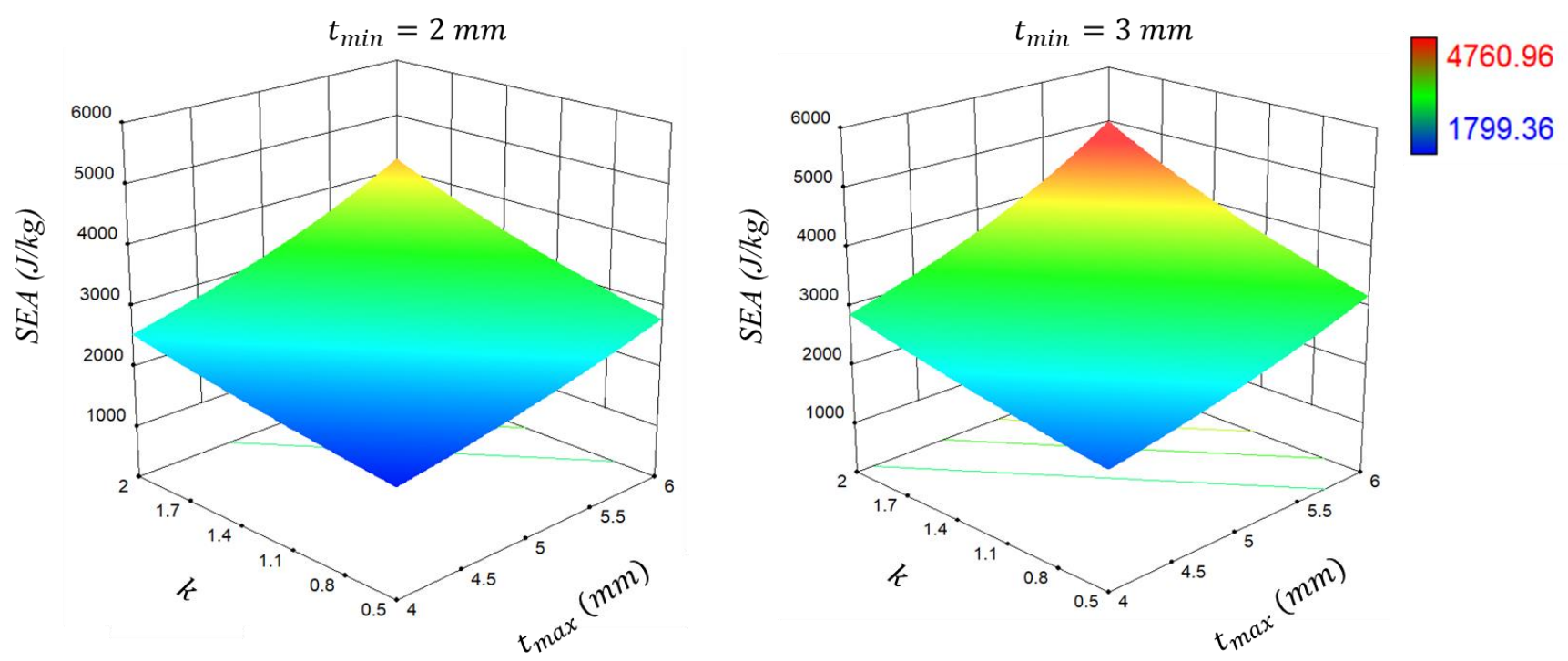
Figure 13: Surface plots showing the variation of PCF with the geometrical parameters of FGT1 design
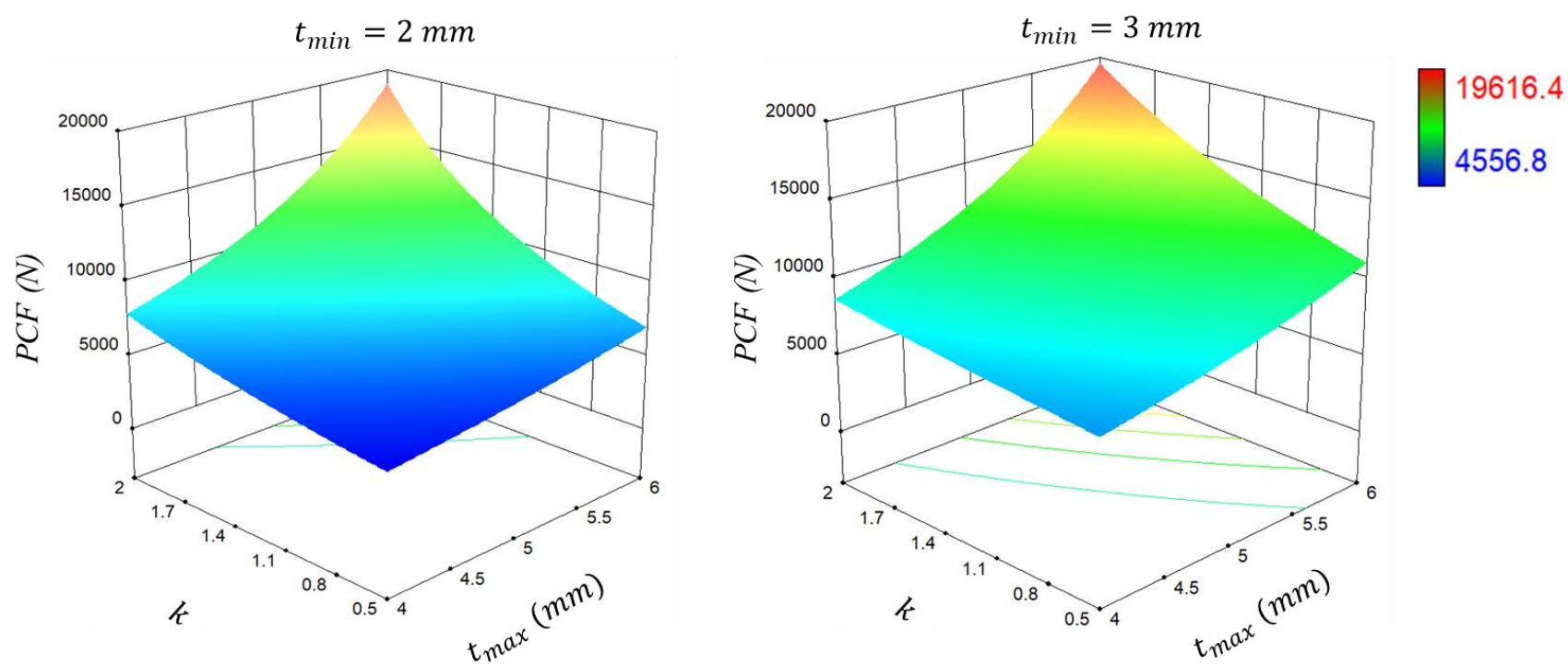
Figure 14: Contour plots showing the variation of desirability objective with the geometrical parameters of FGT1 design

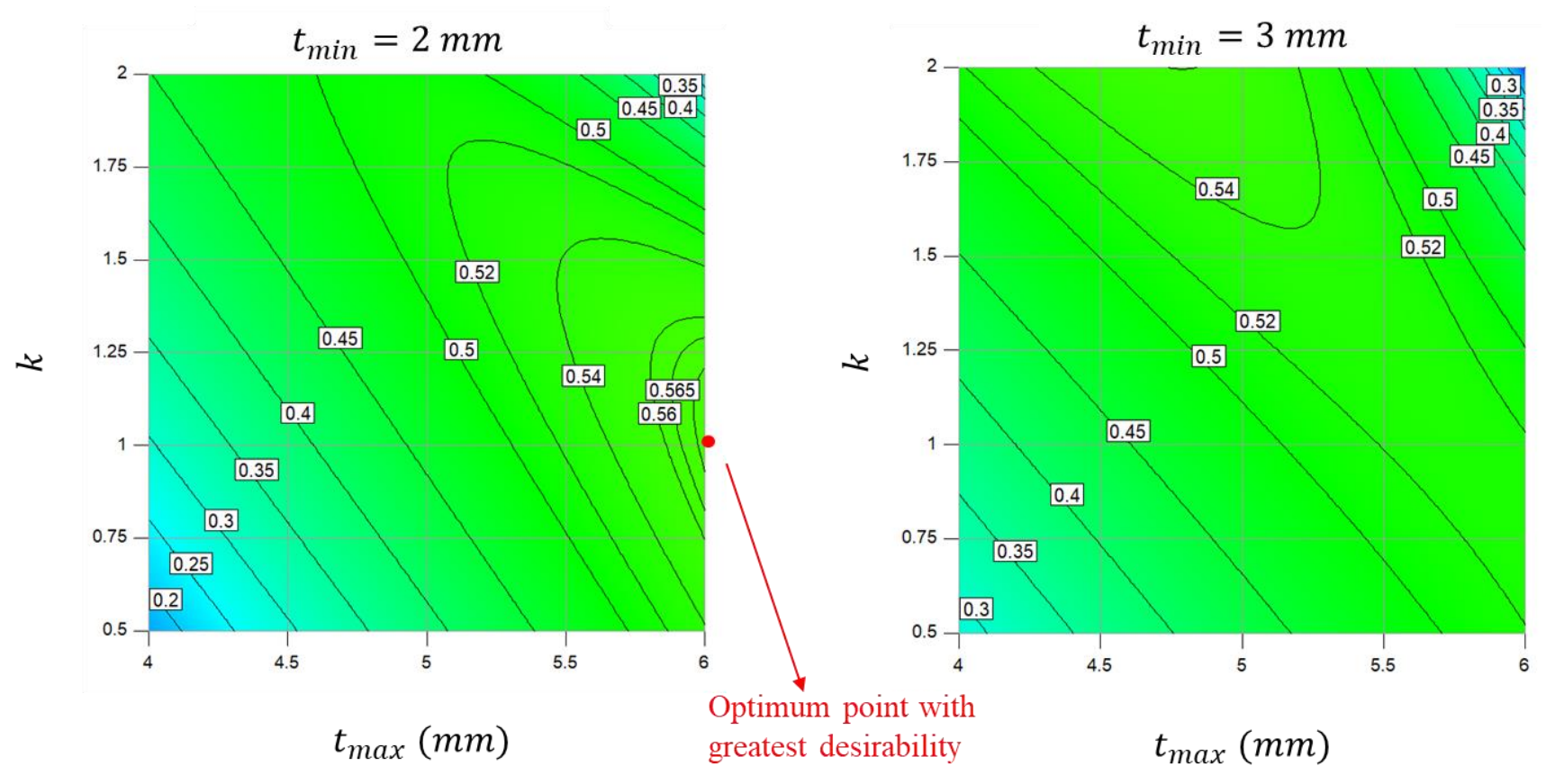

Figure 15: Deformation history of the optimal Ti-FGT1

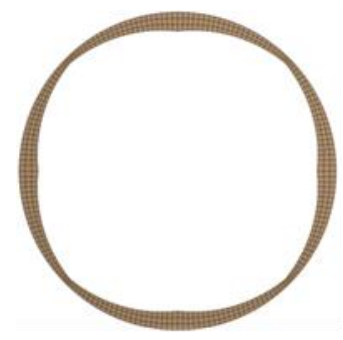

$\delta=0 \mathrm{~mm}$

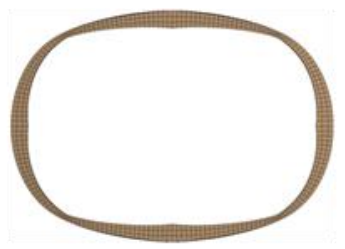

$\delta=20 \mathrm{~mm}$

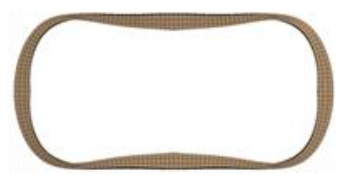

$\delta=40 \mathrm{~mm}$ 
Table 1: Material composition of Ti6Al4V and AlSi10Mg (wt. \%)

\begin{tabular}{cccccccccccc}
\multicolumn{10}{c}{ AlSi10Mg } \\
\hline $\mathrm{Al}$ & $\mathrm{Si}$ & $\mathrm{Fe}$ & $\mathrm{Cu}$ & $\mathrm{Mn}$ & $\mathrm{Mg}$ & $\mathrm{Ni}$ & $\mathrm{Zn}$ & $\mathrm{Pb}$ & $\mathrm{Sn}$ \\
\hline Bal. & $9-11$ & 0.055 & 0.05 & 0.45 & $0.2-0.45$ & 0.05 & 0.1 & 0.05 & 0.05 \\
\hline & & & & & Ti6Al4V & & \\
\hline $\mathrm{Ti}$ & $\mathrm{Al}$ & $\mathrm{V}$ & $\mathrm{O}$ & $\mathrm{N}$ & $\mathrm{C}$ & $\mathrm{H}$ & $\mathrm{Fe}$ & $\mathrm{Y}$ & Other element, each & Other element, each \\
\hline Bal. & $5.5-6.75$ & $3.5-4.5$ & 0.2 & 0.05 & 0.08 & 0.015 & 0.3 & 0.005 & 0.1
\end{tabular}

Table 2: SLM process parameters and scanning strategy

\begin{tabular}{cccccc}
\hline & $\begin{array}{c}\text { Laser power } \\
(\mathrm{W})\end{array}$ & $\begin{array}{c}\text { Scan speed } \\
(\mathrm{mm} / \mathrm{s})\end{array}$ & $\begin{array}{c}\text { Layer thickness } \\
(\mu \mathrm{m})\end{array}$ & $\begin{array}{c}\text { Hatch distance } \\
(\mathrm{mm})\end{array}$ & Scanning strategy \\
\hline Ti6Al4V & 280 & 1200 & 30 & 0.14 & X rotated at $67^{\circ}$ \\
\hline AlSi10Mg & 370 & 1300 & 30 & 0.19 & X rotated at $67^{\circ}$ \\
\hline
\end{tabular}

Table 3: Heat treatment procedure [56,57]

\begin{tabular}{cccc}
\hline & Temperature & Duration (hours) & Atmosphere \\
\hline Ti6Al4V & $650{ }^{\circ} \mathrm{C}$ & 3 hours & Argon \\
\hline AlSi10Mg & $300^{\circ} \mathrm{C}$ & 2 hours & Air \\
\hline
\end{tabular}

Table 4: Mechanical properties of selective laser melted Ti6Al4V and AlSi10Mg alloys

\begin{tabular}{ccc}
\hline & Ti6Al4V & AlSi $10 \mathrm{Mg}$ \\
\hline Elastic modulus & $104.8(\mathrm{GPa})$ & $70(\mathrm{GPa})$ \\
\hline Yield strength & $1112(\mathrm{MPa})$ & $230(\mathrm{MPa})$ \\
\hline Poisson's ratio & 0.3 & 0.3 \\
\hline Bulk density & $4428.78\left(\mathrm{~kg} / \mathrm{m}^{3}\right)$ & $2670\left(\mathrm{~kg} / \mathrm{m}^{3}\right)$ \\
\hline
\end{tabular}


Table 5: Comparison of FE and experimental crashworthiness metrics

\begin{tabular}{cccc}
\hline & & SEA $(\mathrm{J} / \mathrm{kg})$ & $P C F(\mathrm{~N})$ \\
\hline UT & Exp (SP2) & 1912.543 & 8482.629 \\
& FE & 1830.56 & 8421 \\
& Error (\%) & 4.28 & 0.72 \\
\hline FGT1 & Exp (SP1) & 3394.082 & 11328.53 \\
& FE & 3265.8 & 11071.8 \\
& Error (\%) & 3.78 & 2.26 \\
\hline
\end{tabular}

Table 6: Minimum and maximum levels of the design variables

\begin{tabular}{cccc}
\hline & $t_{\max }(\mathrm{mm})$ & $t_{\min }(\mathrm{mm})$ & $\mathrm{k}$ \\
\hline $\operatorname{Min}$ & 4 & 2 & 0.5 \\
\hline $\operatorname{Max}$ & 6 & 3 & 2 \\
\hline
\end{tabular}


Table 7: Design matrix

\begin{tabular}{cccccc} 
Run & $t_{\max }(\mathrm{mm})$ & $t_{\min }(\mathrm{mm})$ & $\mathrm{K}$ & $\mathrm{SEA}(\mathrm{J} / \mathrm{kg})$ & $\mathrm{PCF}(\mathrm{N})$ \\
\hline 1 & 4 & 3 & 2 & 2648.062 & 8778.6 \\
\hline 2 & 4 & 2 & 2 & 2655.055 & 7959 \\
\hline 3 & 6 & 3 & 0.5 & 3270.948 & 11150.2 \\
\hline 4 & 6 & 2 & 0.5 & 2629.212 & 7056.4 \\
\hline 5 & 6 & 2 & 2 & 4659.693 & 19018.6 \\
\hline 6 & 6 & 3 & 2 & 4760.958 & 19616.4 \\
\hline 7 & 4 & 2 & 0.5 & 1799.357 & 4556.8 \\
\hline 8 & 4 & 3 & 0.5 & 2244.794 & 6881.8
\end{tabular}

Table 8: Summary of ANOVA analysis for the generated meta-models of SEA and PCF

\begin{tabular}{ccccc} 
Model & \multicolumn{4}{c}{ Statistical measurements } \\
\cline { 2 - 5 } & $R^{2}$ & Adj- $R^{2}$ & Pre- $R^{2}$ & Adeq Precision \\
\hline$S E A=f\left(t_{\text {max }}, t_{\text {min }}, k\right)$ & 0.95 & 0.92 & 0.92 & 14.79 \\
\hline$P C F=f\left(t_{\text {max }}, t_{\text {min }}, k\right)$ & 0.999 & 0.999 & 0.999 & 3540.75
\end{tabular}

Table 9: Comparison of SEA and PCF obtained from FE simulation and desirability approach for the optimal design

\begin{tabular}{ccc} 
& $S E A(\mathrm{~J} / \mathrm{kg})$ & $P C F(\mathrm{kN})$ \\
\hline Desirability approach & 3207.29 & 9249.9 \\
\hline FE simulation & 3400 & 9800 \\
\hline Error $(\%)$ & 5.67 & 5.61 \\
\hline
\end{tabular}

